\title{
Genome-wide characterization and expression profiling analysis of the xyloglucan endotransglycosylase/hydrolase gene family in Brachypodium distachyon
}

\section{Hongyan Shen}

Shandong Agricultural University

Qiuping Tan

Shandong Agricultural University

Wei Xiao

Shandong Agricultural University

Wenpeng Deng

Shandong Agricultural University

Xiaoyan Yu ( $\square$ yxyxst20040214@163.com )

Shandong Agricultural University

Hongyu Wu ( $\sim 15275380863 @ 163 . c o m$ )

Shandong Agricultural University

\section{Research article}

Keywords: Brachypodium distachyon, Xyloglucan endotransglucosylase/hydrolase, Genome wide analysis, Gene expression

Posted Date: July 29th, 2020

DOI: https://doi.org/10.21203/rs.3.rs-41833/v1

License: (c) (i) This work is licensed under a Creative Commons Attribution 4.0 International License. Read Full License 
6

$7{ }^{1}$ State Key Laboratory of Crop Biology, College of Horticulture Science and

8 Engineering, Shandong Agricultural University, 61 Daizong Road, Tai'an 271018,

9 China

$10{ }^{2}$ State Forestry Administration Key Laboratory of Silviculture in downstream areas of

\section{*Corresponding author}

\section{Hongyu Wu:}

E-mail: 15275380863@163.com

\section{Xiaoyan Yu:}

\section{E-mail: yxyxst20040214@163.com}

distachyon 


\section{Abstract}

Background: Xyloglucan endotransglucosylase/hydrolases (XTHs) are a class of cell wall-associated enzymes involved in the construction and remodeling of cellulose/xyloglucan crosslinks. However, knowledge of this gene family in the model monocot Brachypodium distachyon is limited.

Results: A total of $29 \mathrm{BdXTH}$ genes were identified from the reference genome, and these were further divided into three main groups (Group I/II, Group III, and the Ancestral Group) through comparative phylogenetic analysis. Gene structure and protein motif analysis indicate that closely clustered $B d X T H$ genes are relatively conserved within each group. A highly conserved amino acid domain (DEIDFEFLG) responsible for catalytic activity was identified in all BdXTH proteins. We detected three pairs of segmentally duplicated $B d X T H$ genes and five groups of tandemly duplicated $B d X T H$ genes, which played vital roles in the expansion of the BdXTH gene family. Cis-elements related to hormones, growth, and abiotic stress responses were identified in the promoters of each $B d X T H$ gene. Most $B d X T H$ genes have distinct expression patterns in different tissues and growth stages. Furthermore, when roots were treated with two abiotic stresses (salinity and drought) and four plant hormones (IAA, auxin; GA3, gibberellin; ABA, abscisic acid and BR, brassinolide), the expression levels of many $B d X T H$ genes changed significantly, suggesting possible roles in response to various environmental stimuli and plant hormones.

Conclusion: In this study, we performed genome-wide identification, characterization, and expression pattern analysis of the XTH gene family in Brachypodium, which provide valuable information for further elucidation of the biological functions of $B d X T H$ genes in the model grass $B$. distachyon.

Key worlds: Brachypodium distachyon; Xyloglucan endotransglucosylase/hydrolase; Genome-wide analysis; Gene expression 


\section{Background}

Xyloglucan endotransglucosylase/hydolases (XTHs), a subfamily of the glycoside hydrolase family GH16, are crucial enzymes that are involved in the regulation of cell wall extension, construction, and degradation in plants $[1,2] . \mathrm{XTH}$ proteins have two significant catalytic activities, and can act either as endotransglucosylases (XET, EC 2.4.1.207) to elongate xyloglucan chains by cleaving the chains and rejoining the reducing ends to other xyloglucan molecules, or as endohydrolases (XEH, EC 3.2.1.151) that cleave xyloglucan chains by rejoining the xyloglucan reducing end to water molecules [3]. XTH proteins are predicted to present several common structural features: a putative signal peptide, a conserved ExDxE motif likely to be the catalytic site for both XET and XEH activities, a potential $\mathrm{N}$-glycosylation site necessary for protein stability, and several cysteine residues that stabilize the C-terminal end [4].

The XTH gene family is widely distributed in both monocotyledonous and dicotyledonous plants, and the gene numbers vary within individual plant species, with 33 in Arabidopsis [5], 29 in rice (Oryza sativa) [6], 25 in tomato (Solanum lycopersicum) [7], 44 in Medicago truncatula [8], 26 in woodland strawberry (Fragaria vesca) [9], 56 in tobacco (Nicotiana tabacum) [10], 61 in soybean (Glycine max) [11], 24 in pineapple (Ananas comosus) [12], and 24 in barley (Hordeum vulgare) [13]. A phylogenetic analysis revealed that the XTH proteins cluster into three groups (I, II, and III) on the basis of sequence similarity in A. thaliana [4, 5]. In rice, the XTH proteins were found to cluster into two major groups named I/II and III, because the boundary between group I and II was no longer apparent[14]. Baumann et al. (2007) used 130 full-length XTH protein sequences mainly from Arabidopsis, rice, black cottonwood (Populus trichocarpa), tomato, and hybrid aspen (Populus tremula X Populus tremuloides) to derive a phylogenetic tree from a structure-based sequence alignment using a maximum likelihood method. This study showed that group III can be further separated into two main clades (group III-A and group III-B), and a small outlying ancestral group that is close to the root [15]. Several studies in Fragaria vesca [9], barley [13], and Ananas comosus [12] also reported similar classifications of the XTH proteins. Furthermore, XTH proteins in groups I, II, and 
III-B have been reported to have significant xyloglucan endotransglucosylase (XET) activity, while proteins in group III-A mainly show xyloglucan endohydrolase (XEH) activity [4, 16, 17].

On the one hand, XTH family genes are involved in many physiological responses. For example, DkXTH1, DkXTH4, and DkXTH5 in persimmon shown higher expression levels and are associated with fruit firmness. However, the expression of DkXTH2 and DkXTH3 reach their maxima concomitant with pronounced fruit softening [18]. In addition, overexpression of FvXTH9 and FvXTH6 might promote strawberry fruit ripening by modifying cell wall components [19]. XTH17 and XTH24 in Arabidopsis are involved in polar cell elongation [20]. The natural variation of PtoXET16A in poplar can affect wood properties, and the expression of PtoXET16A in Populus tomentosa was highest in the root, followed by the phloem, cambium, and developing xylem, suggesting that PtoXET16A plays important roles in the development of vascular tissues [21]. On the other hand, $X T H$ family genes also play important roles in the response to plant hormones and abiotic stresses [11, 22]. The expression of Arabidopsis XTH17 was substantially reduced in the presence of aluminum (Al), and the $x$ th 17 and $x$ th 31 mutants were more $\mathrm{Al}$ resistant than the wild type [23]. Expression of DkXTH6 in persimmon (Diospyros kaki) was found to be positively up-regulated during ethylene production, as well as by propylene and ABA treatments, although expression was down-regulated by GA3 and cold treatments. However, the mRNA levels of $D k X T H 7$ were the highest in GA3-treated fruits and cold-treated fruits [24]. In addition, overexpression of persimmon DkXTH1 enhanced tolerance to salt, $\mathrm{ABA}$, and drought stresses in transgenic Arabidopsis plants and delayed fruit softening in transgenic tomatoes [22]. In soybean, the expression levels of many $G m X T H$ genes were significantly associated with ethylene and flooding stress, and overexpression of Arabidopsis XTH31 in soybean can enhance plant flooding tolerance [11].

Brachypodium distachyon is a species of monocot that is used as a model system for genetic and physiological studies in grasses. Plants of $B$. distachyon are small in stature, have a short life cycle, a small genome, modest growth requirements, and 
many available mutant resources [25-29]. Although XTH genes have been reported to play important roles during plant growth and development, little is known about the functions of the $B d X T H$ genes in Brachypodium. The available genome sequence of Brachypodium distachyon and related studies of the XTH gene families from other species will enable the comprehensive characterization of $B d X T H$ genes from $B$. distachyon [30, 31]. In this study, we identified $29 B d X T H$ genes in the B. distachyon genome based on a bioinformatic analysis. We then performed a comprehensive analysis of the $B d X T H$ genes, including their evolutionary relationships, gene structures, duplication events, conserved motifs, and cis-regulatory elements. To provide useful information for further functional studies of the $B d X T H$ genes in $B$. distachyon, the expression patterns of the $X T H$ genes in response to stresses such as plant hormones, salinity, and drought were characterized by qRT-PCR analysis. This study provides novel insights into the functional characteristics of the $B d X T H$ genes in B. distachyon, and also provides necessary resources for further research into the specific functions and regulatory mechanisms of $B d X T H$ genes at different developmental stages.

\section{Results}

\section{Identification of the BdXTH genes in Brachypodium distachyon}

The availability of the $B$. distachyon genome makes it possible to identify the XTH family genes on a genome-wide level. A total of 29 candidate $B d X T H$ genes that are predicted to encode proteins containing both the PF00722 and PF06955 domains were identified. These genes were renamed $B d X T H 1$ to $B d X T H 29$ on the basis of their chromosomal positions (Table 1). The lengths of the BdXTH proteins varied from 279 to 372 amino acids with an average length of 306 amino acids. Corresponding with protein length, the MWs ranged from $30.54 \mathrm{kDa}$ to $40.94 \mathrm{kD}$. Subcellular localization analysis predicted that $27 \mathrm{BdXTH}$ proteins are located in the cell wall, and the other two proteins, BdXTH8 and BdXTH23, are targeted to both the cell wall and the cytoplasm. Owing to the complex amino acid polarities, the PIs ranged from 4.67 to 8.83. Information relating to other parameters of the $\mathrm{BdXTH}$ proteins, such as 
154 instability index (II), aliphatic index (AI), and grand average of hydropathicity 155 (GRAVY) are also presented in Table 1.

156

157

158

159 


\begin{tabular}{|c|c|c|c|c|c|c|c|c|c|c|c|}
\hline Gene Name & Gene ID & Chromosome & Start & End & Length (aa) & MW (kDa) & PI & II & AI & GRAVY & Subcellular Localization \\
\hline BdXTH1 & Bradi1g09690 & $\mathrm{Bd} 1$ & 6944672 & 6946132 & 284 & 31.55 & 5.67 & 36.99 & 63.87 & -0.27 & Cell wall \\
\hline $\mathrm{BdXTH2}$ & Bradi1g09700 & $\mathrm{Bd} 1$ & 6956014 & 6957576 & 284 & 31.54 & 5.67 & 36.12 & 63.87 & -0.26 & Cell wall \\
\hline BdXTH3 & Bradi1g25847 & $\mathrm{Bd} 1$ & 20978556 & 20980916 & 307 & 34.16 & 5.09 & 39.79 & 63.03 & -0.34 & Cell wall \\
\hline BdXTH4 & Bradi1g27867 & $\mathrm{Bd} 1$ & 23074430 & 23076645 & 302 & 34.11 & 8.73 & 40.95 & 58.91 & -0.46 & Cell wall \\
\hline BdXTH5 & Bradi1g33810 & $\mathrm{Bd} 1$ & 29475206 & 29476739 & 290 & 32.39 & 8.78 & 30.99 & 58.24 & -0.42 & Cell wall \\
\hline BdXTH6 & Bradi1g33817 & $\mathrm{Bd} 1$ & 29478854 & 29481513 & 300 & 34.28 & 6.71 & 43.09 & 71.2 & -0.36 & Cell wall \\
\hline BdXTH7 & Bradi1g33827 & $\mathrm{Bd} 1$ & 29485795 & 29487172 & 284 & 31.45 & 5.73 & 38.54 & 62.64 & -0.34 & Cell wall \\
\hline BdXTH8 & Bradi1g33840 & $\mathrm{Bd} 1$ & 29494938 & 29496678 & 293 & 32.59 & 6.22 & 31.26 & 69.66 & -0.28 & Cell wall/Cytoplasm \\
\hline BdXTH9 & Bradi1g44777 & Bd1 & 43043568 & 43045106 & 301 & 33.45 & 5.05 & 43.37 & 68.37 & -0.33 & Cell wall \\
\hline BdXTH10 & Bradi1g68590 & $\mathrm{Bd} 1$ & 67356916 & 67359656 & 328 & 36.46 & 6.02 & 52.51 & 67.65 & -0.39 & Cell wall \\
\hline BdXTH11 & Bradi1g71937 & $\mathrm{Bd} 1$ & 70046381 & 70048307 & 284 & 31.51 & 6.44 & 36.9 & 78.27 & -0.12 & Cell wall \\
\hline BdXTH12 & Bradi1g77990 & $\mathrm{Bd} 1$ & 74331199 & 74332831 & 318 & 35.24 & 7.00 & 46.49 & 61.07 & -0.41 & Cell wall \\
\hline BdXTH13 & Bradi3g02700 & $\mathrm{Bd} 3$ & 1633396 & 1635150 & 336 & 37.66 & 8.57 & 51.44 & 76.10 & -0.22 & Cell wall \\
\hline BdXTH14 & Bradi3g 10290 & $\mathrm{Bd} 3$ & 8496465 & 8498025 & 288 & 32.10 & 4.91 & 32.13 & 66.32 & -0.33 & Cell wall \\
\hline BdXTH15 & Bradi3g18590 & $\mathrm{Bd} 3$ & 17168440 & 17171803 & 280 & 31.02 & 4.91 & 38.97 & 59.21 & -0.38 & Cell wall \\
\hline BdXTH16 & Bradi3g 18600 & $\mathrm{Bd} 3$ & 17175111 & 17176766 & 301 & 33.71 & 5.29 & 28.49 & 60.66 & -0.52 & Cell wall \\
\hline BdXTH17 & Bradi3g18607 & $\mathrm{Bd} 3$ & 17180627 & 17182323 & 291 & 33.41 & 4.85 & 42.45 & 63.68 & -0.51 & Cell wall \\
\hline BdXTH18 & Bradi3g18690 & $\mathrm{Bd} 3$ & 17286604 & 17292191 & 289 & 32.83 & 6.89 & 32.97 & 71.87 & -0.41 & Cell wall \\
\hline BdXTH19 & Bradi3g21337 & $\mathrm{Bd} 3$ & 20473847 & 20476548 & 354 & 39.32 & 8.75 & 48.62 & 75.06 & -0.25 & Cell wall \\
\hline BdXTH20 & Bradi3g31767 & $\mathrm{Bd} 3$ & 20473847 & 20476548 & 289 & 32.32 & 5.78 & 26.27 & 69.24 & -0.26 & Cell wall \\
\hline BdXTH21 & Bradi3g34227 & $\mathrm{Bd} 3$ & 36405786 & 36409262 & 330 & 35.58 & 7.83 & 44.98 & 79.88 & -0.18 & Cell wall \\
\hline BdXTH22 & Bradi3g52307 & $\mathrm{Bd} 3$ & 53017512 & 53019765 & 345 & 37.56 & 8.83 & 33.85 & 64.09 & -0.23 & Cell wall \\
\hline BdXTH23 & Bradi4g 16990 & $\mathrm{Bd} 4$ & 17884860 & 17887177 & 294 & 33.37 & 6.25 & 37.64 & 64.76 & -0.49 & Cell wall/Cytoplasm \\
\hline BdXTH24 & Bradi4g29707 & $\mathrm{Bd} 4$ & 35169644 & 35172434 & 338 & 37.31 & 6.41 & 52.96 & 70.74 & -0.29 & Cell wall \\
\hline
\end{tabular}




\begin{tabular}{llllllllllll}
\hline BdXTH25 & Bradi5g20718 & Bd5 & 23655071 & 23657848 & 316 & 34.23 & 4.67 & 44.62 & 44.62 & -0.19 & Cell wall \\
BdXTH26 & Bradi5g20726 & Bd5 & 23658483 & 23663566 & 372 & 40.94 & 5.79 & 43.33 & 67.96 & -0.25 & Cell wall \\
BdXTH27 & Bradi5g20734 & Bd5 & 23661776 & 23664848 & 295 & 33.66 & 4.83 & 38.07 & 76.41 & -0.29 & Cell wall \\
BdXTH28 & Bradi5g20742 & Bd5 & 23668827 & 23670387 & 279 & 30.54 & 5.19 & 40.05 & 67.89 & -0.26 & Cell wall \\
BdXTH29 & Bradi5g22907 & Bd5 & 25246820 & 25248701 & 314 & 34.27 & 5.37 & 31.8 & 73.34 & -0.25 & Cell wall \\
\hline
\end{tabular}




\section{Phylogenetic analysis of BdXTH proteins}

To study the evolutionary relationships among XTH proteins in dicots and monocots, a phylogenetic tree was constructed using the full-length candidate XTH protein sequences in Brachypodium and other three species, including 29 BdXTHs, 33 AtXTHs from Arabidopsis, 30 OsXTHs from rice, and 36 SIXTHs from tomato (Table S1). The results showed that the XTH proteins cluster into three main groups (Group I/II, Group III, and Ancestral Group), and that each phylogenetic group contains XTH proteins from the four species (Fig. 1). Not unexpectedly, proteins from closely related species clustered together; proteins from the monocots (B. distachyon and rice) tended to cluster together and proteins from the dicots (tomato and Arabidopsis) clustered together. Furthermore, the different groups contained different numbers of XTH proteins. Group I/II contained the largest number of XTH proteins, including 19 BdXTHs, 18 OsXTHs, 22 AtXTHs, and 27 SIXTHs. Group III was further divided into two subgroups (Group III-A and Group III-B), which included two and six BdXTHs, respectively, along with XTH proteins from the other three species included in the analysis. The Ancestral Group contains the smallest number of XTH proteins; two BdXTHs, one OsXTH, four AtXTHs, and two SIXTHs.

\section{Structural and conserved motif analyses of the $B d X T H$ genes}

Different combinations of exons and introns can lead to diverse gene functions. To gain more knowledge of the structural diversity of the $B d X T H$ genes, the structures of the $29 B d X T H$ genes were analyzed using GSDS. The results showed that the number of exons varied from three to five, and that the structures of genes from the same group showed more similarity to one another (Fig. 2b). Most of the BdXTH genes (20/29) contained three exons. Eight genes contained four exons and only one gene (BdXTH19) in Group III-B contained five exons. In addition, only BdXTH26 from Group I/II contained two longer introns. Moreover, three genes (BdXTH15, 18, and 27) from Group I/II had longer UTR sequences compared with the other genes.

A conserved motif analysis of all 29 predicted BdXTH protein sequences from $B$. distachyon conducted using the MEME program predicted 20 motifs (Fig. 3; Fig. S1); 
191 the number of motifs varied from nine to thirteen, and members of the same group usually shared a similar motif composition. The proteins in Group III-A and the 193 Ancestral Group had relatively fewer motifs, nine and ten, respectively, while most of the XTH proteins in the other groups had 12 motifs. Motifs 1, 3, and 4 were found to be highly conserved in all BdXTH proteins. In addition, several conserved motifs were specific to certain groups. For example, motifs 10, 13, and 17-19 were only present in Group I/II proteins, and motifs 15 and 16 were unique to proteins in Group III-B.

\section{Chromosomal location and synteny analysis of the $B d X T H$ genes}

The chromosomal positions of $29 B d X T H$ genes were located using information derived from the Brachypodium genome [30]. The BdXTH genes were found to be widely distributed on the chromosomes, but the distribution was not uniform (Fig. 3). None of the $B d X T H$ genes were located on Chr. 2. Only two BdXTH gens were located on Chr. 4, and five $B d X T H$ genes were located on the end of Chr. 5. In addition, most $B d X T H$ genes were located on Chrs. 1 and 3, with 12 and 10 genes, respectively.

To identify potential duplication events in the $B d X T H$ gene family, a collinearity analysis was performed using MCScanX software. Results revealed that there are three pairs of segmentally duplicated $B d X T H$ genes (BdXTH15/25, BdXTH17/27, and $B d X T H 18 / 27$ ) and five groups of tandemly duplicated $B d X T H$ genes (Fig. 4; BdXTH1/2, BdXTH5/6/7/8, BdXTH15/16, BdXTH25/26, and BdXTH27/28). BdXTH15, B. distachyon.

\section{Structure-based sequence alignment}


BdXTH protein sequences with those of two other proteins for which the structures have been experimentally determined (PttXET16-34, PDB id: 1UN1 and TmNXG1, PDB

id:

2UWA)

[15,

32],

using

ESPript

\section{4} (http://espript.ibcp.fr/ESPript/cgi-bin/ESPript.cgi). This analysis showed that the active site $(\underline{E} \underline{\operatorname{Dx}} \underline{\mathrm{E}})$ responsible for catalytic activity is highly conserved in all of the BdXTH protein family members (Fig. 4; Fig. S2; Fig. S3). The first glutamate residue (E) is the catalytic nucleophile that initiates the enzymatic reaction, and the second $\mathrm{E}$ residue acts as a base to activate the entrant substrate. The $N$-glycosylation site denominated as NxT/S/Y (marked with asterisks) can bind $N$-glycans and is related to protein stability. We found that the $\mathrm{N}$-glycosylation site was present in almost all BdXTH proteins except the Ancestral Group members (BdXTH9 and BdXTH11). We also found that the distance between the $N$-glycosylation site and the active site in the Group I/II members was closer than in the Group III members. The BdXTH proteins also contain conserved domains next to the substrate binding site that are called loop 1, loop 2, and loop 3 (underlined in green). Loop 2 in the Group III-A proteins (BdXTH4 and BdXTH12) is longer compared to that in the other groups, which may be the reason why proteins in Group III-A mainly show xyloglucan hydrolase activity.

\section{Cis-element analysis of the $B d X T H$ gene promoter regions}

XTH family genes play important roles during plant growth and development, as well as in the response to multiple environmental stresses. Cis-elements can regulate gene expression via their interactions with the trans-acting elements such as transcription factors. To understand the functions and regulation network of the $B d X T H$ family genes, we analyzed the 2,000 bp of DNA sequence upstream of the promoter regions for $29 B d X T H$ genes on the PlantCARE database [33]. As shown in Fig. 5, the promoter regions include several hormone-related (abscisic acid, MeJA, auxin, salicylic acid, and gibberellin) cis-elements (ABRE, CGTCA-motif, TGACG-motif, TGA-element, AuxRR-core, TCA-element, P-box, GARE-motif, TATC-box), and growth regulation cis-elements (MBSI, RY-element, CAT-box, HD-Zip 1, O2-site, GCN4_motif, MSA-like, circadian motif I). The promoter regions also contain several 
environmental response elements, such as those for anaerobic (ARE), drought (MBS), low temperature (LTR), and anoxic (GC-motif) conditions; light responsive elements (GT1-motif); and defense and stress (TC-rich repeats) cis-elements. The distribution of cis-elements analyzed in the promoter regions is shown in Fig. S4. Cis-acting elements involved in the responses to phytohormones were relatively abundant, especially the abscisic acid-responsive (ABRE) element, and accounted for $27 \%$ of the total number of cis-elements detected in this study. The cis-elements involved in cell cycle regulation (MSA-like), root development (motif I), and flavonoid biosynthesis gene regulation (MBSI) were only found in the promoter regions of several Group I/II genes. In addition, two Group III-B genes (BdXTH22, BdXTH19) contain the highest (36) and lowest (14) numbers of cis-elements identified, respectively.

\section{Expression patterns of the $B d X T H$ genes in various tissues}

To explore the temporal and spatial expression patterns of the BdXTH genes in Brachypodium, RNA-seq data including expression profiles from various tissues and developmental stages (leaf, inflorescence, anther, pistil, seed, embryo, and endosperm) were downloaded from the NCBI database (SRP008505). Based on the clusters in the phylogenetic tree, the expression patterns of genes from the same group tended to be different, and most of the $B d X T H$ genes exhibited distinct tissue-specific expression patterns (Fig. 6). For example, the $B d X T H 21 / 26 / 27$ genes are mainly expressed in the endosperm, $B d X T H 1 / 2$ are mainly expressed in the seed, $B d X T H 8 / 9$ are mainly expressed in the pistil, $B d X T H 7 / 13 / 17$ are mainly expressed in the anther, and $B d X T H 3 / 4 / 14 / 19 / 23 / 24 / 29$ are mainly expressed in the inflorescence, whereas expression levels were found to be relatively low in other organs, suggesting that the functions of some genes are redundant and that certain genes participate in the developmental progress of specific tissues. In addition, three genes (BdXTH11/20/28) all showed lower expression levels at almost all developmental stages and in almost all tissues included in the study. 

phytohormone treatments using qRT-PCR

283 Previous studies have shown that the expression of XTH family genes can respond to multiple abiotic stresses and phytohormones. To investigate the effect of different treatment conditions on $B d X T H$ gamily genes, qRT-PCR assays were performed to study the expression patterns of 29 BdXTH genes in response to drought (PEG), salinity $(\mathrm{NaCl}$ ), and four plant hormones (ABA, BR, IAA, and GA3) (Fig. 7). Analysis of the data showed that the expression levels of many genes were affected by the different treatments. For the PEG and $\mathrm{NaCl}$ treatments, the expression patterns of the BdXTH genes were similar. Among the up-regulated genes, BdXTH7/11/13/15/19/21/25 showed relatively higher mRNA levels, in which BdXTH11 (Ancestral Group) had the highest expression level under both stress treatments. In addition, almost all of the genes that were down-regulated in response to PEG treatment, such as $B d X T H 1-6 / 12 / 16 / 17 / 20 / 23 / 27$, also showed relatively lower expression levels under $\mathrm{NaCl}$ treatment. For the phytohormone treatments, BdXTH19 from Group III-B showed the highest mRNA levels in response to BR, IAA, and GA3 treatments, and BdXTH7 from Group I/II showed the highest level when treated with ABA. The altered expression patterns of the $B d X T H$ genes suggests that they might be involved in adapting to adverse environmental factors, or are regulated by diverse plant hormones.

\section{Discussion}

Xyloglucan endotransglucosylase/hydrolases (XTHs), one family of cell-wall-modifying enzymes, can cut and/or rejoin xyloglucan molecules to regulate the composition and organization of the cell wall [34]. In this study, $29 B d X T H$ genes were identified in the Brachypodium genome, and a phylogenetic analysis showed that they are organized into three major groups (Group I/II, Group III, and the Ancestral Group). A similar XTH protein classification was also reported in strawberry (Fragaria vesca) [9], barley (Hordeum vulgare) [13], and pineapple (Ananas comosus) [12]. The number of BdXTH genes in Brachypodium was similar to 
the number of $X T H$ genes identified previously in other species, such as Arabidopsis [5] , rice (29) [14], and strawberry (26) [9], but was much lower than the number of $X T H$ genes in tobacco (56) [10], soybean (61) [11], and wheat (57) [35]. Duplication events (tandem duplication or segmental duplication events) resulting from whole genome duplication (WGD) via polyploidization or local chromosomal rearrangement played an important role in $X T H$ gene family expansion and evolution. Duplication events are likely to have arisen in an immediate common ancestor, and duplicated genes tend to have a closer relationship. The phylogenetic tree showed that all of the genes arising from tandem or segmental duplication events are clustered together and impact genes belonging to Group I/II, which is the largest group compared to the other groups. For example, the tandemly duplicated gene pairs BdXTH1/2 and $B d X T H 5 / 6 / 7 / 8$ on chromosome 1, BdXTH15/16 on chromosome 3, BdXTH25/26 and $B d X T H 27 / 28$ on chromosome 5, and the segmentally duplicated gene pairs $B d X T H 15 / 25, B d X T H 17 / 27$, and $B d X T H 18 / 27$ are all members of Group I/II.

The BdXTH proteins in each group contain relatively conserved motifs and the genes structures are also conserved, suggesting that $\mathrm{BdXTH}$ proteins in the same group may perform similar functions (Fig. 2; Fig. 4). The results of secondary structure prediction for the translated $\mathrm{BdXTH}$ sequences confirms the existence of a highly conserved domain (DEIDFEFLG) that is the catalytic site for both XET and XEH activities [4], especially the three absolutely conserved catalytic residues (ExDxE) in all BdXTH proteins. Also, the $\mathrm{N}$-glycosylation site in $\mathrm{BdXTH}$ proteins from Group I/II is adjacent to the catalytic domain, but tended to be located towards the carboxyl terminus in Group III-B proteins. In addition, loop 2 in Group III-A protein is longer compared to that in Group III-B members, which has been proposed to be a major structural change responsible for the endo-hydrolase activity of these proteins [15]. Previous studies have reported that XTH proteins in Group III-A mainly display XEH activity $[16,17,36]$, while Group I/II and Group III-B proteins mainly shown XET activity [37].

A comparison of the predicted $X T H$ gene amino acid sequences from $B$. distachyon, rice (Oryza sativa), tomato (Solanum lycopersicum), and Arabidopsis (A. thaliana) 
revealed the high degree of conservation of the XTH sequences among various plant species, implying a general functional conservation of these proteins in the plant kingdom. Our phylogenetic analysis revealed that all clades contained proteins from both the monocot (Brachypodium and rice) and dicot (tomato and Arabidopsis) species included in the analysis. This suggests that the precursor genes were present in the most recent common ancestor of monocots and dicots, and that closely related proteins might perform similar functions in the different species, although xyloglucan makes up a relatively smaller fraction of the cell wall in Poales species $[6,38]$.

Analysis of the genomic sequences upstream of the BdXTH genes using the PlantCARE tool revealed that a series of cis-elements involved in the responses to hormones and abiotic stresses, and also in growth and development, are present in the promoter regions, indicating that $B d X T H$ genes play diverse roles in Brachypodium. Clearly, $B d X T H$ genes respond to drought, salinity, and several plant hormones (ABA, BR, IAA, and GA3) based on the changes in gene expression patterns observed in the qRT-PCR experiment (Fig. 7), which corroborate the results of the analyses of BdXTH gene promoter regions. Expression profiling suggests that $B d X T H$ genes might be involved in adaptation to adverse environmental conditions, or that they are regulated by many plant hormones. In addition, transcriptional analysis of $B d X T H$ genes in several tissues and at different development stages from an existing RNA-seq dataset showed tissue, organ, and temporal specificity, but correlations between phylogenetic groups and specific tissue expression patterns were weak (Fig. 6). For example, $B d X T H 1,8,17,23$, and 27 are all members of Group I/II, but they are expressed at high levels in seeds, pistils, anthers, early inflorescences, and the endosperm, respectively. Also, many of the segmentally-duplicated gene pairs with close evolutionary relationships have different expression patterns. For example, the expression of $B d X T H 15$ is at its highest in the inflorescence and seed, but the highest expression levels of $B d X T H 25$ are found in the anther and endosperm. BdXTH27 showed its highest expression level in the endosperm, but the expression of $B d X T H 28$ was low in all tissues examined in this study. These results suggest that genes in the $B d X T H$ family might have undergone neofunctionalization or sub-functionalization 
371 during evolution. The specific function and molecular analysis of each gene will 372 require further study.

\section{Conclusions}

375 In this study, we performed a genome-wide analysis of the $B d X T H$ gene family in 376 Brachypodium and investigated the expression profiles of all 29 genes in different tissues and developmental stages, as well as in response to various stress conditions. Many of the $B d X T H$ genes exhibit distinct tissue-specific expression patterns, indicating that various $B d X T H$ genes may play a universal cell wall modification function in specific tissues and during specific stages of development. In addition, the changes in the relative expression of most $B d X T H$ genes in response to diverse abiotic stresses provides an indication of the possible functions of $B d X T H$ genes in response to drought, salinity, and several phytohormones. These results may advance our understanding of the role of $B d X T H$ genes in the regulation of Brachypodium growth and development and also in its response to abiotic stresses.

\section{Methods}

\section{Identification of the $X T H$ family genes in $B$. distachyon}

The latest version of the Brachypodium distachyon (v3.1) genome annotations was downloaded from the Phytozome database (https://phytozome.jgi.doe.gov/pz/portal.html) [39]. The Hidden Markov Model (HMM) profiles of the XTH protein domains, PF00722 and PF06955, were downloaded from the Pfam database [40], and were used as queries to search the database using the program HMMER3.0 with the default E-value. The online program SMART (http://smart.embl-heidelberg.de/) [41] and the PFAM databases (https://pfam.xfam.org) [42] were used to identify the conserved domains of candidate Brachypodium XTH proteins. Only proteins containing both the PF00722 and PF06955 domains were retained for further study. ProtParam (http://web.expasy.org/protparam/) was used to predict the physical and chemical 
401 features of the BdXTH proteins. The subcellular locations of the BdXTH proteins

402

403

404

405

406

407

408

409

410

411

412

413

were predicted using the online website Plant-mPLoc in Cell-PLoc 2.0 (http://www.csbio.sjtu.edu.cn/bioinf/Cell-PLoc-2/) [43]. All of the XTH protein sequences from tomato, Arabidopsis, and rice were also downloaded from the Phytozome database (https://phytozome.jgi.doe.gov/pz/portal.html). The corresponding gene IDs of the XTH protein family members are given in Table S1.

Phylogenetic tree construction

A phylogenetic tree was constructed using the Neighbor Joining (NJ) method as implemented in MEGA-X software, and the branch support was estimated by bootstrapping with 1,000 replicates [44].The $\mathrm{NJ}$ tree was constructed from an alignment of 128 amino acid sequences of predicted XTH proteins, of which 29 BdXTHs were from B. distachyon, 36 SIXTHs were from S. lycopersicum, 30 OsXTHs were from $O$. sativa, and 33 AtXTHs were from A. thaliana (Table S1). The phylogenetic tree was then visualized using iTol (https://itol.embl.de/) [45].

Gene structures, conserved protein motifs, and cis-acting regulatory element analysis

The $B d X T H$ gene structures were displayed using the Gene Structure Display Server (GSDS) tool (http://gsds.cbi.pku.edu.cn/) [46] by aligning the cDNA sequences and the corresponding genomic DNA sequences. The Multiple EM for Motif Elicitation (MEME, http://meme-suite.org/) [47] was used to search for possible conserved motifs in the complete amino acid sequences of predicted BdXTH proteins using the default settings. Additionally, the cis-elements in the $B d X T H$ gene promoter regions (2,000-bp of genomic sequence upstream of the coding sequences) were analyzed using the

PlantCARE database (http://bioinformatics.psb.ugent.be/webtools/plantcare/html/) [33].

\section{Chromosomal location and gene duplication}

The chromosomal positions of BdXTH genes were acquired from the Brachypodium distachyon genome (v3.1). MCScanX (default parameters) [48] was used to analyze gene duplications using the amino acid sequences and chromosomal location data. The chromosomal locations and gene duplication relationships of the $B d X T H$ genes 
were displayed using TBtools (https://github.com/CJ-Chen/TBtools) [49].

\section{Structural-based sequence alignment analysis}

Alignment of the identified BdXTH protein sequences with two other proteins, TmNXG1 (PDB id: 2UWA) and PttXET16-34 (PDB id: 1UN1), for which the structures have been experimentally determined, was performed to identify common structural elements. The crystal structures of TmNXG1and PttXET16-34 were obtained from the PDB databank (www.pdb.org). The secondary structures of the $\mathrm{BdXTH}$ proteins were then predicted using the online website ESPript (http://espript.ibcp.fr/ESPript/ESPript/) [50].

\section{Expression pattern analysis of $B d X T H$ genes using RNA-seq data}

RNA-seq data from various Brachypodium tissues and developmental stages (leaves, pre- and post-emergence flowers, anthers, pistils, whole seeds at 5 days after pollination, whole seeds at 10 days after pollination, embryos at 25 days after pollination, and endosperm at 25 days after pollination) were downloaded from the NCBI database (SRP008505) [51] to analyze the expression patterns of the different $B d X T H$ genes. The heat maps and hierarchical clustering were created by TBtools (https://github.com/CJ-Chen/TBtools) [49] using FPKM values extracted from the RNA-seq dataset.

\section{Plant materials and treatments}

Seeds of Brachypodium distachyon (ecotype Bd21) provided by Professor Hailong An of Shandong Agricultural University were placed on wet filter paper and maintained for 3 days at $4^{\circ} \mathrm{C}$ in the dark, after which they were cultivated in a plant growth incubator under long-day conditions $\left(18 \mathrm{~h} \mathrm{light} / 6 \mathrm{~h}\right.$ dark) at $20^{\circ} \mathrm{C}$ for one week. The young seedlings were then transferred to custom-made plastic vessels with holes in the bottoms suspended on the surface of a reservoir containing 0.5X MS liquid medium and maintained in a growth chamber under the same conditions (18 h light/6 $\mathrm{h}$ dark, $20^{\circ} \mathrm{C}$ ). Seedlings with three leaves were subjected to different abiotic stress and phytohormone treatments, which included $150 \mathrm{mM} \mathrm{NaCl}, 20 \%$ polyethylene glycol (PEG) 6000, $1 \mu \mathrm{M}$ 3-indole acetic acid (IAA), $1 \mu \mathrm{M}$ gibberellic acid $\left(\mathrm{GA}_{3}\right), 1$ $\mu \mathrm{M}$ abscisic acid (ABA), and $1 \mu \mathrm{M}$ 24-epibrassinolide (BR). Roots of the 

stress-treated and control plants were collected after $2 \mathrm{~h}$ of treatment. All of the materials were immediately frozen in liquid nitrogen and stored at $-80^{\circ} \mathrm{C}$ prior to RNA extraction. Every sample comprised three independent biological replications. RNA isolation and qRT-PCR gene expression analysis

465 The frozen samples were ground to powder in liquid nitrogen with a mortar and pestle. Total RNA was isolated from roots using the RNAprep Pure Plant Kit (Tiangen, 467 Beijing, China) and first-strand total cDNA was then synthesized using the HiScript ${ }^{\circledR}$ II Q RT SuperMix for qPCR (+gDNA wiper) Kit (Vazyme, China). Beacon designer software was used to design the gene-specific primers for qRT-PCT (Table S2). Real-time qRT-PCR assays were performed using ChamQ ${ }^{\mathrm{TM}} \mathrm{SYBR}^{\circledR}$ qPCR Master Mix (Vazyme, China) on a Bio-Rad CFX96 Real-time PCR System (Bio-Rad, USA). The $B d U B C 18$ gene was used as the internal control for normalization of gene expression. Each PCR contained $0.4 \mu \mathrm{L}$ of each primer, $1 \mu \mathrm{L}$ of template cDNA and $10 \mu \mathrm{L}$ of 2 XChamQ SYBR qPCR Master Mix in a final volume of $20 \mu \mathrm{L}$. The thermal cycling protocol was as follows: $95^{\circ} \mathrm{C}$ for $30 \mathrm{~s}$ followed by 40 cycles of $95{ }^{\circ} \mathrm{C}$ for $10 \mathrm{~s}$ and $60{ }^{\circ} \mathrm{C}$ for $30 \mathrm{~s}$. Subsequently, melting curves were performed to confirm the specificity of the primers. Each reaction was performed three times, and the $2^{-\Delta \Delta \mathrm{Ct}}$ 


\section{Declarations}

492

493

494

495

496

497

498

499

500

501

502

503

504

505

506

507

508

509

510

511

512

513

514

515

516

517

518

519

520

\section{Abbreviations}

XTH: Xyloglucan endotransglucosylase/hydrolase; IAA: Auxin; GA3: Gibberellin; ABA: Abscisic acid; BR: Brassinolide; MW: Molecular weight; MeJA: Methyl jasmonate; PEG: Polyethylene glycol; qRT-PCR: Quantitative real time polymerase chain reaction; GSDS: Gene Structure Display Server; NJ: Neighbour-Joining

\section{Acknowledgements}

We thank Professor Hailong An for providing Brachypodium distachyon (ecotype Bd21) seeds.

\section{Authors' contributions}

HW and XY designed the research. HS, QT, WX and WD performed the research and analyzed the data. HS wrote the manuscript. HW and XY revised the manuscript. All authors have read and approved the manuscript.

\section{Funding}

This work was financially supported by the Introduction and Training Plan of Young Creative Talents in Universities of Shandong Province: Research Group of Forest Tree Biotechnology $(\mathrm{CN})$. The funding body was not involved in the design of the study; collection, analysis, or interpretation of data; or manuscript writing.

\section{Availability of data and materials}

All of the data and materials supporting our research findings are contained in the methods section of the manuscript. Details are provided in the attached additional files.

\section{Ethics approval and consent to participate}

Not applicable.

\section{Consent for publication}

Not applicable.

\section{Competing interests}

The authors declare that they have no competing interests. 
References

1. Van Sandt VS, Suslov D, Verbelen JP, Vissenberg K: Xyloglucan endotransglucosylase activity loosens a plant cell wall. Annals of botany 2007, 100(7):1467-1473.

2. Cantarel BL, Coutinho PM, Rancurel C, Bernard T, Lombard V, Henrissat B: The Carbohydrate-Active EnZymes database (CAZy): an expert resource for Glycogenomics. Nucleic acids research 2009, 37(Database issue):D233-238.

3. Eklöf JM, Brumer $H$ : The XTH gene family: an update on enzyme structure, function, and phylogeny in xyloglucan remodeling. Plant Physiol 2010, 153(2):456-466.

4. Campbell P, Braam J: Xyloglucan endotransglycosylases: diversity of genes, enzymes and potential wall-modifying functions. Trends in plant science 1999, 4(9):361-366.

5. Yokoyama R, Nishitani $\mathrm{K}$ : A comprehensive expression analysis of all members of a gene family encoding cell-wall enzymes allowed us to predict cis-regulatory regions involved in cell-wall construction in specific organs of Arabidopsis. Plant \& cell physiology 2001, 42(10):1025-1033.

6. Hara Y, Yokoyama R, Osakabe K, Toki S, Nishitani K: Function of xyloglucan endotransglucosylase/hydrolases in rice. Annals of botany 2014, 114(6):1309-1318.

7. Saladié M, Rose JK, Cosgrove DJ, Catalá C: Characterization of a new xyloglucan endotransglucosylase/hydrolase (XTH) from ripening tomato fruit and implications for the diverse modes of enzymic action. The Plant journal : for cell and molecular biology 2006, 47(2):282-295.

8. Xuan Y, Zhou ZS, Li HB, Yang ZM: Identification of a group of XTHs genes responding to heavy metal mercury, salinity and drought stresses in Medicago truncatula. Ecotoxicology and environmental safety 2016, 132:153-163.

9. Opazo MC, Lizana R, Stappung Y, Davis TM, Herrera R, Moya-León MA: XTHs from Fragaria vesca: genomic structure and transcriptomic analysis in ripening fruit and other tissues. BMC genomics 2017, 18(1):852.

10. Wang $\mathrm{M}, \mathrm{Xu} \mathrm{Z}$, Ding $\mathrm{A}$, Kong $\mathrm{Y}$ : Genome-Wide Identification and Expression Profiling Analysis of the Xyloglucan Endotransglucosylase/Hydrolase Gene Family in Tobacco (Nicotiana tabacum L.). Genes 2018, 9(6).

11. Song L, Valliyodan B, Prince S, Wan J, Nguyen HT: Characterization of the XTH Gene Family: New Insight to the Roles in Soybean Flooding Tolerance. International journal of molecular sciences 2018, 19(9).

12. Li Q, Li H, Yin C, Wang X, Jiang Q, Zhang R, Ge F, Chen Y, Yang L: Genome-Wide Identification and Characterization of Xyloglucan Endotransglycosylase/Hydrolase in Ananas comosus during Development. Genes 2019, 10(7).

13. Fu MM, Liu C, Wu F: Genome-Wide Identification, Characterization and 
Expression Analysis of Xyloglucan Endotransglucosylase/Hydrolase Genes Family in Barley (Hordeum vulgare). Molecules 2019, 24(10).

14. Yokoyama R, Rose JK, Nishitani K: A surprising diversity and abundance of xyloglucan endotransglucosylase/hydrolases in rice. Classification and expression analysis. Plant Physiol 2004, 134(3):1088-1099.

15. Baumann MJ, Eklöf JM, Michel G, Kallas AM, Teeri TT, Czjzek M, Brumer $\mathrm{H}$, 3rd: Structural evidence for the evolution of xyloglucanase activity from xyloglucan endo-transglycosylases: biological implications for cell wall metabolism. The Plant cell 2007, 19(6):1947-1963.

16. Zhu XF, Shi YZ, Lei GJ, Fry SC, Zhang BC, Zhou YH, Braam J, Jiang T, Xu $\mathrm{XY}$, Mao CZ et al: XTH31, encoding an in vitro XEH/XET-active enzyme, regulates aluminum sensitivity by modulating in vivo XET action, cell wall xyloglucan content, and aluminum binding capacity in Arabidopsis. The Plant cell 2012, 24(11):4731-4747.

17. Kaewthai N, Gendre D, Eklöf JM, Ibatullin FM, Ezcurra I, Bhalerao RP, Brumer H: Group III-A XTH genes of Arabidopsis encode predominant xyloglucan endohydrolases that are dispensable for normal growth. Plant Physiol 2013, 161(1):440-454.

18. Han Y, Zhu Q, Zhang Z, Meng K, Hou Y, Ban Q, Suo J, Rao J: Analysis of xyloglucan endotransglycosylase/hydrolase (XTH) genes and diverse roles of isoenzymes during persimmon fruit development and postharvest softening. PLoS One 2015, 10(4):e0123668.

19. Witasari LD, Huang FC, Hoffmann T, Rozhon W, Fry SC, Schwab W: Higher expression of the strawberry xyloglucan endotransglucosylase/hydrolase genes FvXTH9 and FvXTH6 accelerates fruit ripening. The Plant journal : for cell and molecular biology 2019, 100(6):1237-1253.

20. Lee YK, Rhee JY, Lee SH, Chung GC, Park SJ, Segami S, Maeshima M, Choi G: Functionally redundant LNG3 and LNG4 genes regulate turgor-driven polar cell elongation through activation of XTH17 and XTH24. Plant molecular biology 2018, 97(1-2):23-36.

21. Wang B, Zhang D: Association of allelic variation in PtoXET16A with growth and wood properties in Populus tomentosa. International journal of molecular sciences 2014, 15(9):16949-16974.

22. Han Y, Han S, Ban Q, He Y, Jin M, Rao J: Overexpression of persimmon DkXTH1 enhanced tolerance to abiotic stress and delayed fruit softening in transgenic plants. Plant Cell Rep 2017, 36(4):583-596.

23. Zhu XF, Wan JX, Sun Y, Shi YZ, Braam J, Li GX, Zheng SJ: Xyloglucan Endotransglucosylase-Hydrolase17 Interacts with Xyloglucan Endotransglucosylase-Hydrolase31 to Confer Xyloglucan Endotransglucosylase Action and Affect Aluminum Sensitivity in Arabidopsis. Plant Physiol 2014, 165(4):1566-1574.

24. Han Y, Ban Q, Hou Y, Meng K, Suo J, Rao J: Isolation and Characterization of Two Persimmon Xyloglucan 
Endotransglycosylase/Hydrolase (XTH) Genes That Have Divergent Functions in Cell Wall Modification and Fruit Postharvest Softening. Frontiers in plant science 2016, 7:624.

25. Opanowicz M, Vain P, Draper J, Parker D, Doonan JH: Brachypodium distachyon: making hay with a wild grass. Trends in plant science 2008, 13(4):172-177.

26. Ozdemir BS, Hernandez P, Filiz E, Budak H: Brachypodium genomics. International journal of plant genomics 2008, 2008:536104.

27. Brkljacic J, Grotewold E, Scholl R, Mockler T, Garvin DF, Vain P, Brutnell T, Sibout $\mathrm{R}$, Bevan $\mathrm{M}$, Budak $\mathrm{H}$ et al: Brachypodium as a model for the grasses: today and the future. Plant Physiol 2011, 157(1):3-13.

28. Hsia MM, O'Malley R, Cartwright A, Nieu R, Gordon SP, Kelly S, Williams TG, Wood DF, Zhao Y, Bragg J et al: Sequencing and functional validation of the JGI Brachypodium distachyon T-DNA collection. The Plant journal : for cell and molecular biology 2017, 91(3):361-370.

29. Wu H, Xue X, Qin C, Xu Y, Guo Y, Li X, Lv W, Li Q, Mao C, Li L et al: An Efficient System for Ds Transposon Tagging in Brachypodium distachyon. Plant Physiol 2019, 180(1):56-65.

30. International Brachypodium I: Genome sequencing and analysis of the model grass Brachypodium distachyon. Nature 2010, 463(7282):763-768.

31. Gordon SP, Contreras-Moreira B, Woods DP, Des Marais DL, Burgess D, Shu S, Stritt C, Roulin AC, Schackwitz W, Tyler L et al: Extensive gene content variation in the Brachypodium distachyon pan-genome correlates with population structure. Nature communications 2017, 8(1):2184.

32. Johansson P, Brumer H, 3rd, Baumann MJ, Kallas AM, Henriksson H, Denman SE, Teeri TT, Jones TA: Crystal structures of a poplar xyloglucan endotransglycosylase reveal details of transglycosylation acceptor binding. The Plant cell 2004, 16(4):874-886.

33. Lescot M, Déhais P, Thijs G, Marchal K, Moreau Y, Van de Peer Y, Rouzé P, Rombauts S: PlantCARE, a database of plant cis-acting regulatory elements and a portal to tools for in silico analysis of promoter sequences. Nucleic acids research 2002, 30(1):325-327.

34. Rose JK, Braam J, Fry SC, Nishitani K: The XTH family of enzymes involved in xyloglucan endotransglucosylation and endohydrolysis: current perspectives and a new unifying nomenclature. Plant \& cell physiology 2002, 43(12):1421-1435.

35. Liu Y, Liu D, Zhang H, Gao H, Guo X, Wang D, Zhang X, Zhang A: The alpha- and beta-expansin and xyloglucan endotransglucosylase/hydrolase gene families of wheat: molecular cloning, gene expression, and EST data mining. Genomics 2007, 90(4):516-529.

36. Fanutti C, Gidley MJ, Reid JS: Action of a pure xyloglucan endo-transglycosylase (formerly called xyloglucan-specific endo-(1-->4)-beta-D-glucanase) from the cotyledons of germinated nasturtium seeds. The Plant journal : for cell and molecular biology 1993, 
3(5):691-700.

37. Maris A, Suslov D, Fry SC, Verbelen JP, Vissenberg K: Enzymic characterization of two recombinant xyloglucan endotransglucosylase/hydrolase (XTH) proteins of Arabidopsis and their effect on root growth and cell wall extension. $J$ Exp Bot 2009, 60(13):3959-3972.

38. Carpita NC, Gibeaut DM: Structural models of primary cell walls in flowering plants: consistency of molecular structure with the physical properties of the walls during growth. The Plant journal : for cell and molecular biology 1993, 3(1):1-30.

39. Goodstein DM, Shu S, Howson R, Neupane R, Hayes RD, Fazo J, Mitros T, Dirks W, Hellsten U, Putnam N et al: Phytozome: a comparative platform for green plant genomics. Nucleic acids research 2012, 40(Database issue):D1178-1186.

40. Punta M, Coggill PC, Eberhardt RY, Mistry J, Tate J, Boursnell C, Pang N, Forslund $\mathrm{K}$, Ceric $\mathrm{G}$, Clements $\mathrm{J}$ et al: The Pfam protein families database. Nucleic acids research 2012, 40(Database issue):D290-301.

41. Letunic I, Doerks T, Bork P: SMART 7: recent updates to the protein domain annotation resource. Nucleic acids research 2012, 40(Database issue):D302-305.

42. El-Gebali S, Mistry J, Bateman A, Eddy SR, Luciani A, Potter SC, Qureshi M, Richardson LJ, Salazar GA, Smart A et al: The Pfam protein families database in 2019. Nucleic acids research 2019, 47(D1):D427-D432.

43. Chou KC, Shen HB: Plant-mPLoc: a top-down strategy to augment the power for predicting plant protein subcellular localization. PLoS One 2010, 5(6):e11335.

44. Kumar S, Stecher G, Li M, Knyaz C, Tamura K: MEGA X: Molecular Evolutionary Genetics Analysis across Computing Platforms. Molecular biology and evolution 2018, 35(6):1547-1549.

45. Letunic I, Bork P: Interactive tree of life (iTOL) v3: an online tool for the display and annotation of phylogenetic and other trees. Nucleic acids research 2016, 44(W1):W242-245.

46. Hu B, Jin J, Guo AY, Zhang H, Luo J, Gao G: GSDS 2.0: an upgraded gene feature visualization server. Bioinformatics 2015, 31(8):1296-1297.

47. Bailey TL, Johnson J, Grant CE, Noble WS: The MEME Suite. Nucleic acids research 2015, 43(W1):W39-49.

48. Wang Y, Tang H, Debarry JD, Tan X, Li J, Wang X, Lee TH, Jin H, Marler B, Guo $\mathrm{H}$ et al: MCScanX: a toolkit for detection and evolutionary analysis of gene synteny and collinearity. Nucleic acids research 2012, 40(7):e49.

49. Chen C, Chen H, Zhang Y, Thomas HR, Frank MH, He Y, Xia R: TBtools an integrative toolkit developed for interactive analyses of big biological data. Mol Plant 2020.

50. Robert X, Gouet P: Deciphering key features in protein structures with the new ENDscript server. Nucleic acids research 2014, 42(Web Server 
issue):W320-324.

51. Davidson RM, Gowda M, Moghe G, Lin H, Vaillancourt B, Shiu SH, Jiang N, Robin Buell C: Comparative transcriptomics of three Poaceae species reveals patterns of gene expression evolution. The Plant journal : for cell and molecular biology 2012, 71(3):492-502.

52. Livak KJ, Schmittgen TD: Analysis of relative gene expression data using real-time quantitative PCR and the 2(-Delta Delta C(T)) Method. Methods 2001, 25(4):402-408.

\section{Figure legends}

Fig. 1 Phylogenetic relationships among XTH proteins from Brachypodium and three other plant species. The phylogenetic tree was constructed with the Neighbor Joining (NJ) method as implemented in MEGA-X software, and branch confidence was estimated by bootstrapping with 1,000 replicates. The open blue, gray, red, and black circles indicate proteins from Brachypodium, rice, tomato, and Arabidopsis, respectively. In addition, the XTH proteins are classified into three clades (Group I/II, Group III, and the Ancestral Group). Proteins in Group I/II and the Ancestral Group are shown with purple and blue backgrounds, respectively. Group III is further divided into two subclades, Group III-A and Group III-B, which are indicated with red and green backgrounds, respectively.

Fig. 2 Unrooted neighbor-joining phylogenetic tree, conserved protein motifs, and structural analysis of $\boldsymbol{B d X T H}$ genes. (a) Phylogenetic relationships of the XTH proteins in Brachypodium. Proteins from the four clades (Group I/II, Group III-A and Group III-B, and the Ancestral Group) are color coded as in Figure 1. (b) The structures of the 29 putative $B d X T H$ genes. The UTRs, exons, and introns are represented by green boxes, yellow boxes, and black lines, respectively. (c) Conserved motif analysis of the BdXTH proteins. The different motifs are indicated by different colored boxes numbered motif 1 to motif 20 . The structural features of the 20 motifs are shown in Fig S1.

Fig. 3 The physical locations of BdXTH genes on the five Brachypodium chromosomes. Tandemly duplicated gene pairs and segmentally duplicated genes are linked by red lines. The chromosome numbers are displayed at the top of each chromosome and the scale in megabases $(\mathrm{Mb})$ is shown on the left. 
Fig. 4 Structure-based sequence alignment of BdXTH proteins. The structures of two proteins (PttXET16-34, PDB id: 1UN1; TmNXG1, PDB id: 2UWA) have been experimentally determined. Proteins in Group I/II and the Ancestral Group had similar structures to 1UN1, and proteins in Group III show similar structures to 2UWA. The active site (ExDxE), and loops 1, 2, and 3 are underlined in black and green, respectively. The $\mathrm{N}$-glycosylation site residues are indicated by asterisks.

Fig. 5 Numbers of cis-acting elements in the promoter regions of the $29 \mathrm{BdXTH}$ genes. Three types of $c i$-acting elements in the 2,000 bp of DNA sequence upstream of the promoter regions are shown in the figure, including phytohormone- and environmentally-responsive elements and plant growth and development-related elements. Members of the different element classes are shown at the top of the figure in different shades of gray.

Fig. 6 Heat map showing the expression pattern of BdXTH genes in Brachypodium. Expression profiles from various tissues and developmental stages (leaves, early inflorescences, emerging inflorescences, anthers, pistils, seeds at 5 days after pollination, seeds at 10 days after pollination, embryos, and endosperm) were downloaded from the NCBI database (SRP008505). The relative expression levels are represented by the colored bars. Red and green boxes indicate high and low expression levels, respectively.

Fig. 7 Expression analysis of $B d X T H$ genes under different conditions. Quantitative real-time polymerase chain reaction (qRT-PCR) analysis of $B d X T H$ gene expression in response to abiotic stresses (drought and salinity) (a), and phytohormone treatments (ABA, BR, IAA, and GA3) (b). The means \pm SD of three biological replicates are presented.

Fig. S1 Sequence logos of 20 conserved motifs detected in the BdXTH proteins.

The overall height of each stack represents the degree of conservation at that position, and the height of the individual letter within each stack indicates the relative frequency of the corresponding amino acid.

Fig. S2 Multiple alignment of deduced amino acid sequences of BdXTH proteins from Group I/II, the Ancestral Group and 1UN1. 
Fig. S3 Multiple alignment of deduced amino acid sequences of BdXTH proteins from Group III and 2UWA.

Fig. S4 Cis-acting elements identified in the 2,000 bp of sequence upstream of the promoter regions of the $B d X T H$ genes.

Table 1 The physicochemical properties of XTH gamily genes in Brachypodium.

Table S1 Identification of $X T H$ gene family members from three plant species.

Table S2 Oligonucleotide primers used for qRT-PCR assays in this study. 
Fig. 1

802

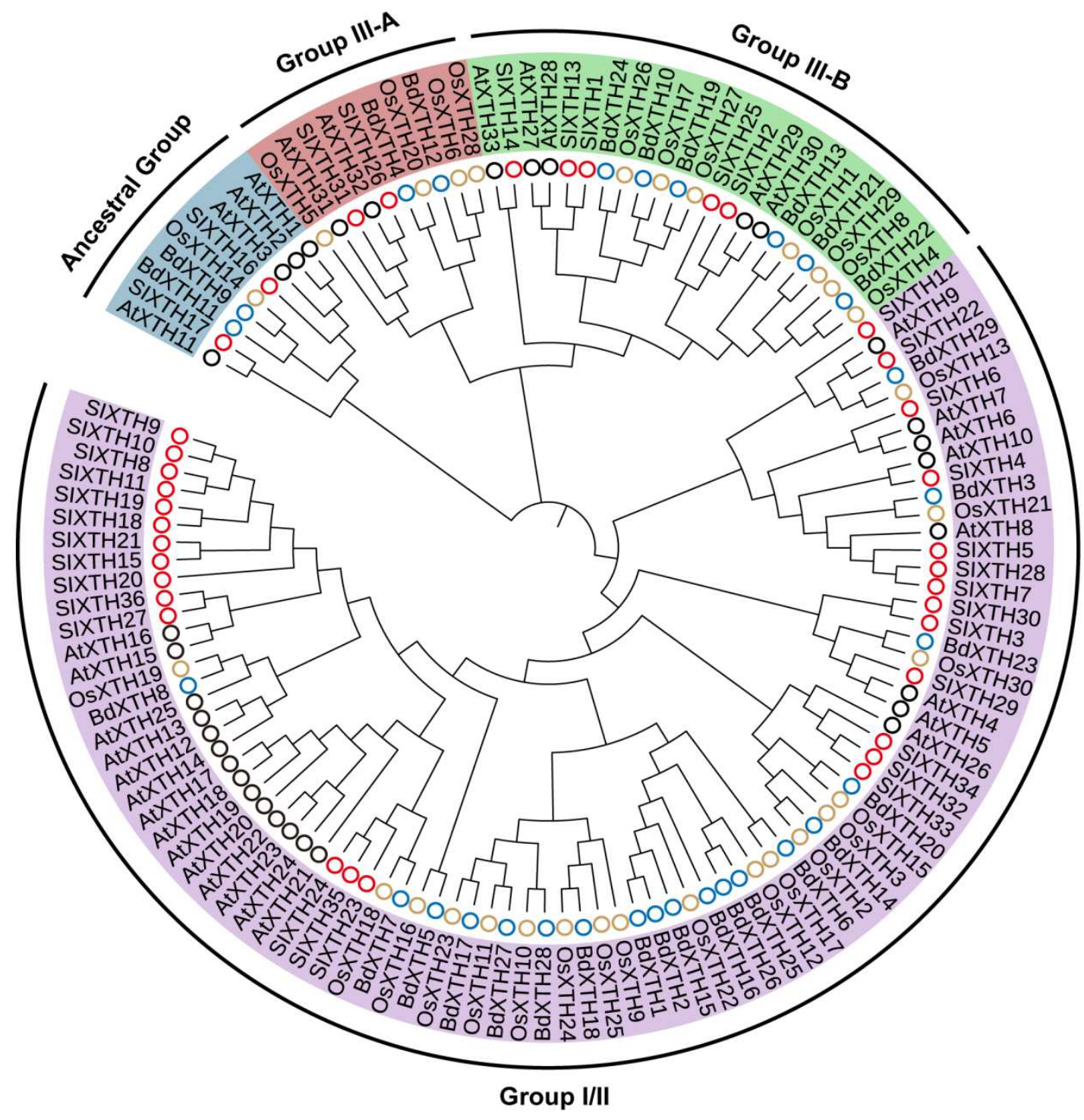

803

804

805

806

807

808

809

810

811

812

813

814

815

816 
818 Fig. 2

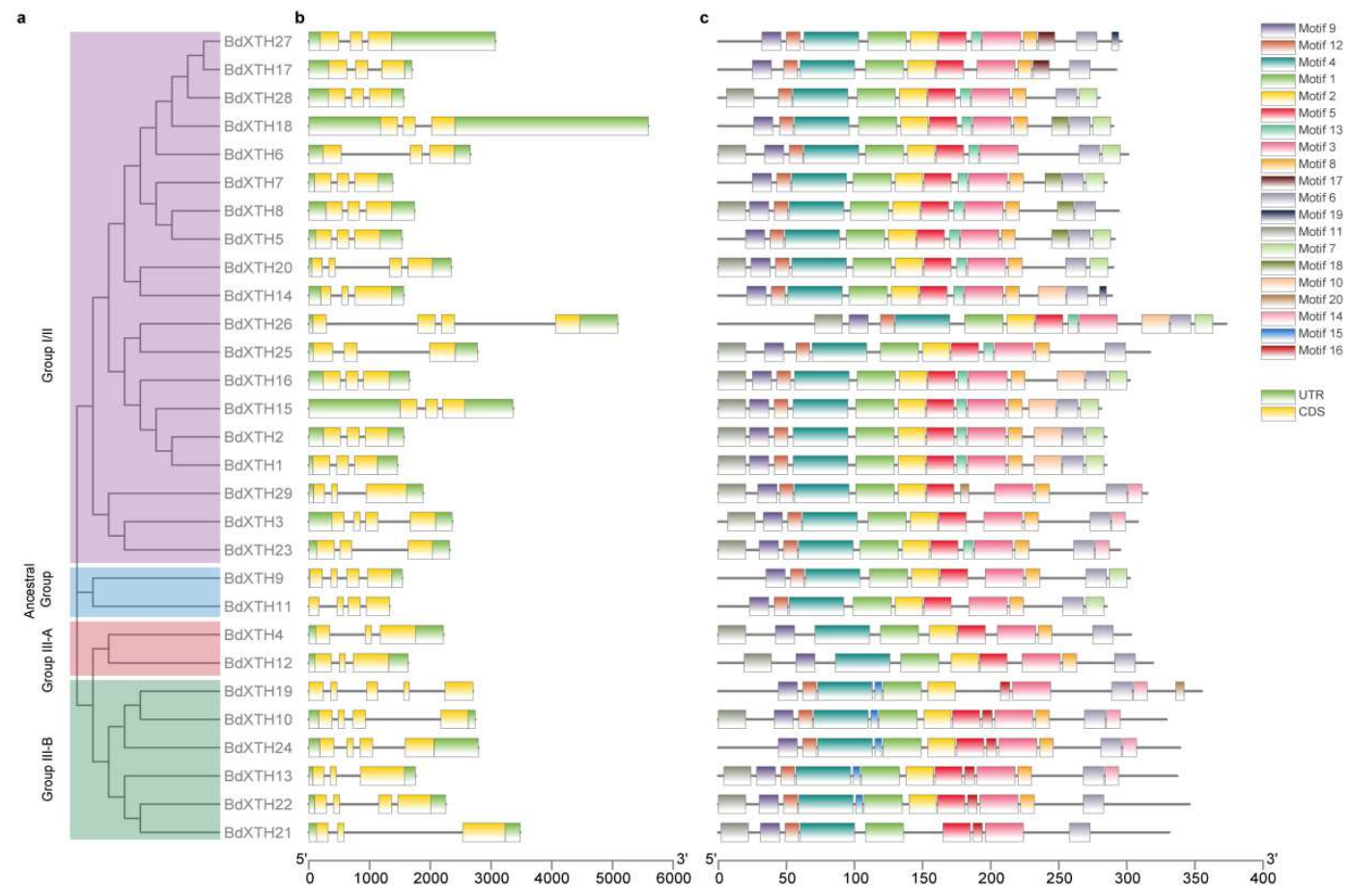

819

820

821

822

823

824

825

826

827

828

829

830

831

832

833

834

835

836

837

838

839

840

841

842

843

844 
Fig. 3

846
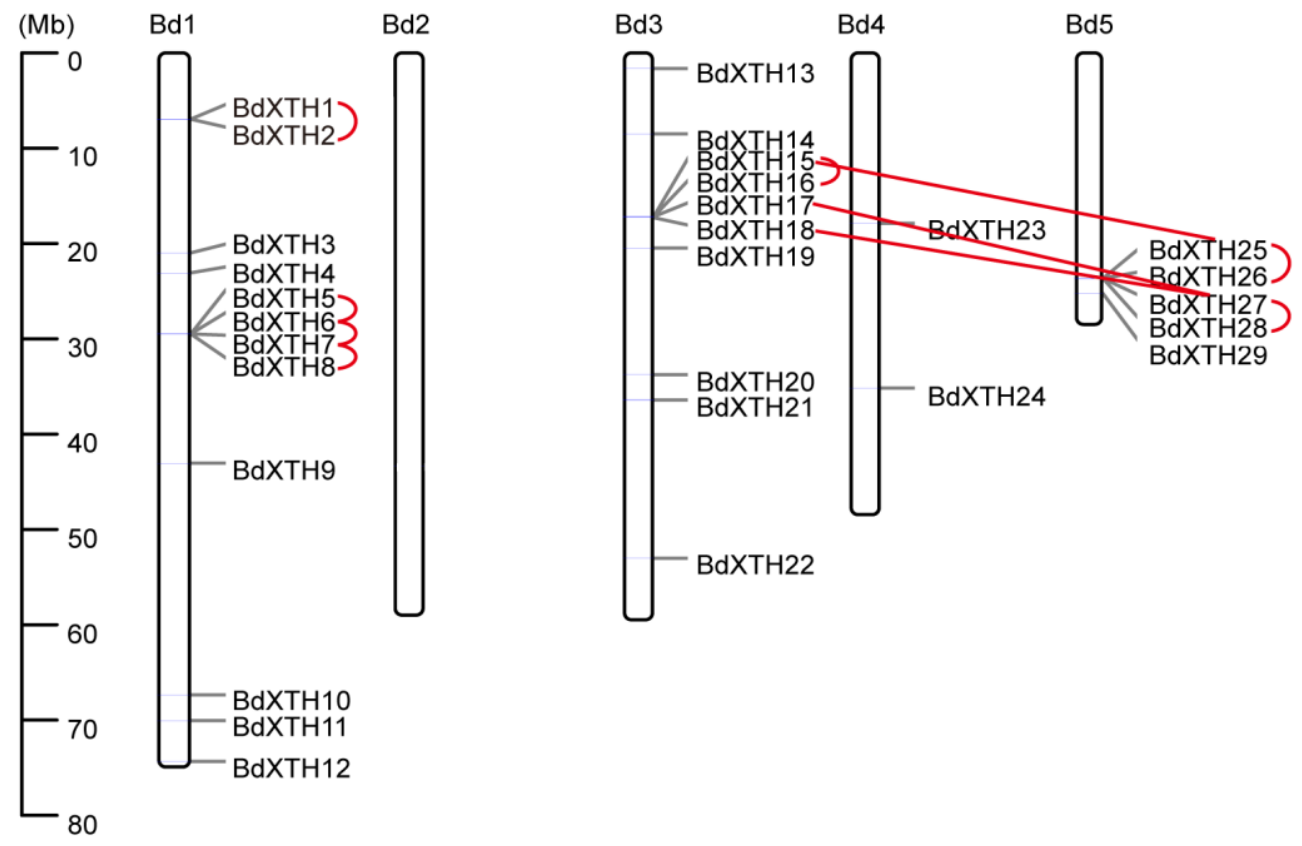

847

848

849

850

851

852

853

854

855

856

857

858

859

860

861

862

863

864

865

866

867

868

869

870

871

872 


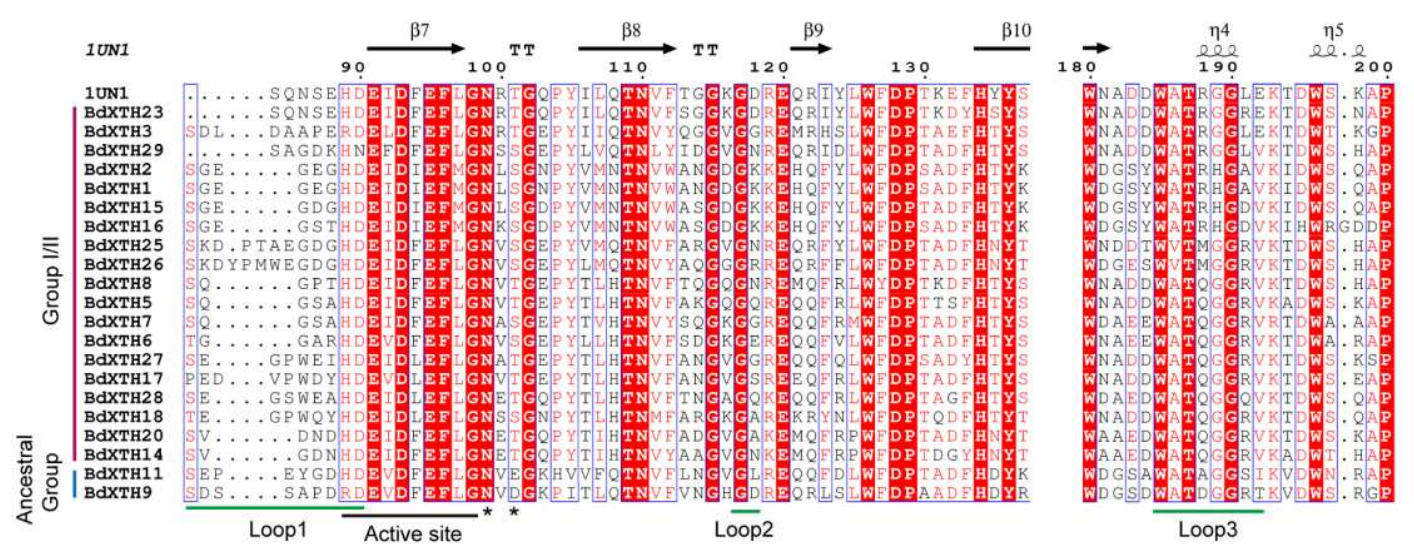

874
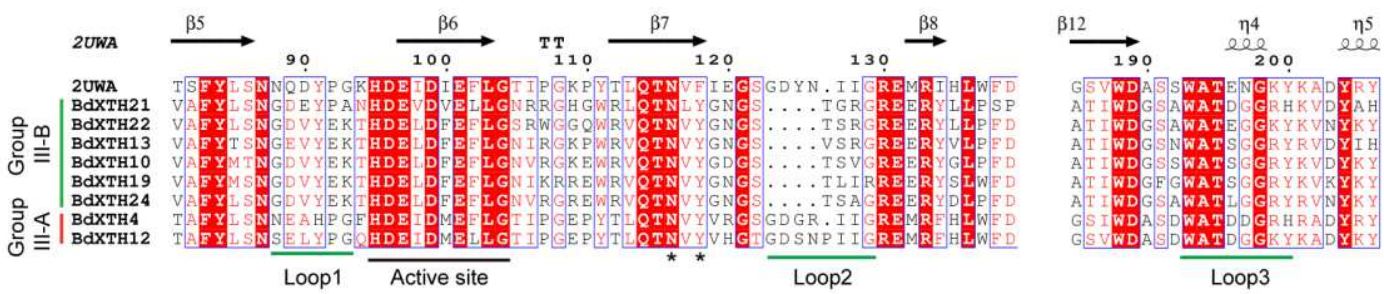

875

876

877

878

879

880

881

882

883

884

885

886

887

888

889

890

891

892

893

894

895

896

897

898

899

900 
Fig. 5

BdXTH1

$\mathrm{BdXTH2}$

$\mathrm{BdXTH3}$

BdXTH5

BdXTH6

$\mathrm{BdXTH7}$

BdXTH8

BdXTH14

BdXTH15

BdXTH16

BdXTH17

$\mathrm{BdXTH} 18$

$\mathrm{BdXTH2O}$

$\mathrm{BdXTH23}$

BdXTH25

BdXTH26

$\mathrm{BdXTH} 27$

$\mathrm{BdXTH} 28$

똥을

$\mathrm{BdXTH29}$

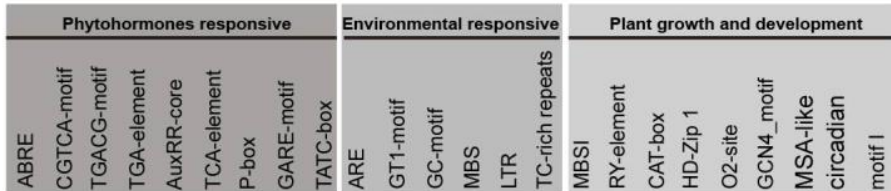

BdXTH9

BdXTH11

III-A BdXTH4

BdXTH12

\begin{tabular}{|l|l|l|l|l|l|l|l|l|l|l|l|l|l|l|l|l|l|l|l|l|l|l|l|}
1 & 1 & 1 & & & & & & & 4 & 3 & 1 & 2 & & & 1 & & 1 & 1 & 1 & & & & \\
\hline 6 & & & 1 & & 1 & 2 & & & & 2 & 1 & & 1 & & & & 1 & & & & &
\end{tabular}

\begin{tabular}{|l|l|l|l|l|l|l|l|l|l|l|l|l|l|l|l|l|l|l|l|l|l|l|}
\hline 6 & & & 1 & & 1 & 2 & & & 2 & 1 & & 1 & & & 1 & & & & & \\
\hline 3 & 4 & 4 & 1 & & & & & 1 & & & & & & 1 & & & 1 & & \\
\hline
\end{tabular}

6 \begin{tabular}{l|l|l|l|l}
6 & 2 & 2 & 1 \\
7 & 3 & 3 & 1 & 0
\end{tabular}

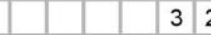

\begin{tabular}{|l|l|l|l|}
7 & 3 & 3 & 1 \\
\hline 6 & 1 & & 1 \\
\hline & 3 & 3 & -1 \\
\hline
\end{tabular}

4 \begin{tabular}{lll|}
4 & 3
\end{tabular}

\begin{tabular}{l|l|l|l|}
15 & 6 & 6 & 1
\end{tabular}

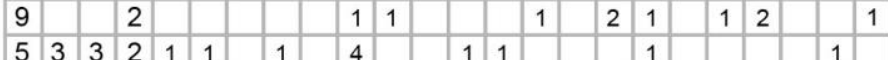

\begin{tabular}{|l|l|l|l|l|l|l|l|l|l|l|}
\hline 4 & 1 & 1 & 1 & 1 & & & & 2 \\
\hline
\end{tabular}

\begin{tabular}{|l|l|l|l|l|l|l|l|l|l|}
\hline 4 & 1 & 1 & 2 & & 1 & & & 1 & 4 \\
\hline 7 & 1 & 1 & & & & 1 & 1 & & 1 \\
\hline
\end{tabular}

\begin{tabular}{lll|l}
7 & 1 & 1 \\
11 & 2 & 2
\end{tabular}

\begin{tabular}{l|l|l|}
11 & 2 & 2
\end{tabular}

\begin{tabular}{|l|l|l|l|l|l|l|l|l|l|}
\hline 9 & 1 & 1 & 2 & 1 & 1 & & 1 & & 1 \\
\hline 3 & 3 & 3 & 1 & & & & & & 3 \\
\hline
\end{tabular}

\begin{tabular}{ll|l|l|}
5 & 6 & 6 & 1 \\
\hline 11 & 5 & 5 &
\end{tabular}

\begin{tabular}{l|l|l|}
11 & 5 & 5
\end{tabular}

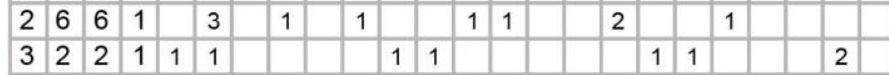

BdXTH10

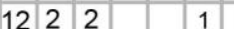

\begin{tabular}{l|l|l|l|l|l}
12 & 2 & 2 \\
\hline 10 & 2 & 2 & 0 \\
\hline & & 2 & 0
\end{tabular}

10 \begin{tabular}{l|l|l}
10 & 2 \\
3 & 3 & 3
\end{tabular}

$\mathrm{BdXTH13}$

$\mathrm{BdXTH} 19$

\begin{tabular}{lll|l}
3 & 3 & 3
\end{tabular}

$\mathrm{BdXTH} 21$

$\mathrm{BdXTH} 22$

BdXTH24

\begin{tabular}{c|c|c|c|c|c|c|c|c|c|c|c|c|c|c|c|c|c|c|c|c|c|c|c|}
\hline 2 & 2 & 2 & 1 & 2 & 1 & 2 & 1 & & 4 & 1 & & & 1 & & & 1 & & & & 1 & & \\
\hline & 3 & 3 & & & 1 & & & & 3 & 1 & & 1 & & & & & 1 & & & 1 & & \\
\hline 7 & 8 & 8 & 1 & & 1 & & & & & & & 2 & & 2 & & 1 & 1 & 1 & & \\
\hline 10 & 7 & 7 & 2 & & 2 & & & 1 & 3 & & 2 & & 1 & & & 1 & & & & \\
\hline 2 & 2 & 2 & & & 1 & & & & 2 & 3 & & 2 & & & & 1 & & & & \\
\hline
\end{tabular}

903

904

905

906

907

908

909

910

911

912

913

914

915

916

917

918

919

920

921 
Fig. 6

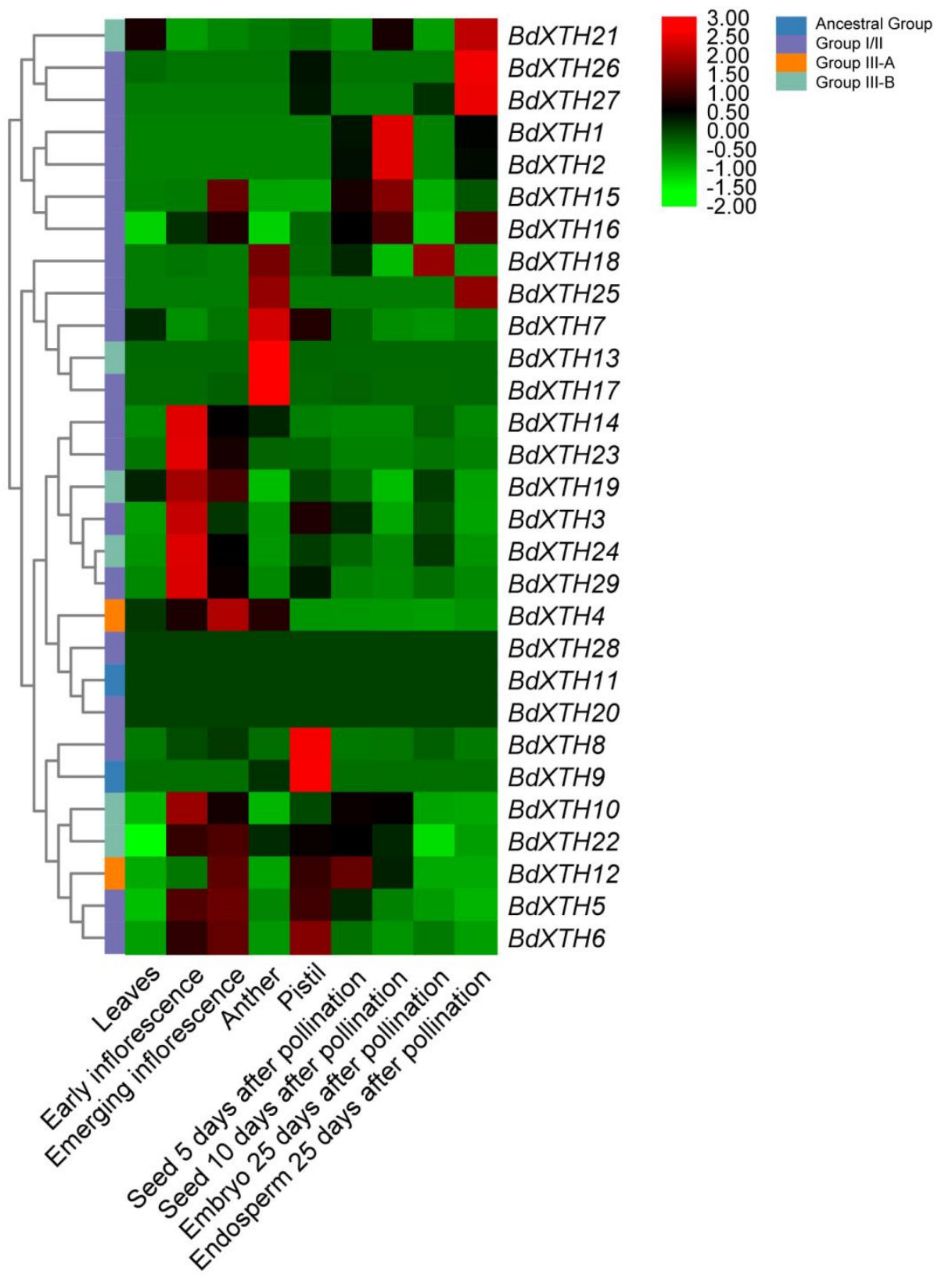


Fig. 7

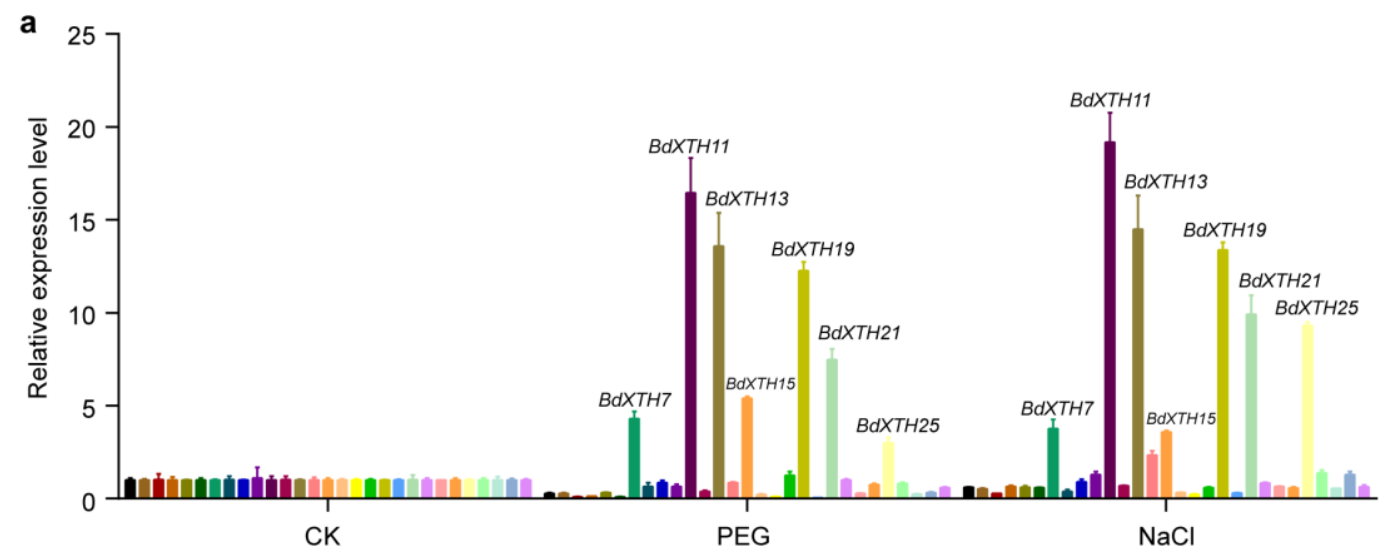

b

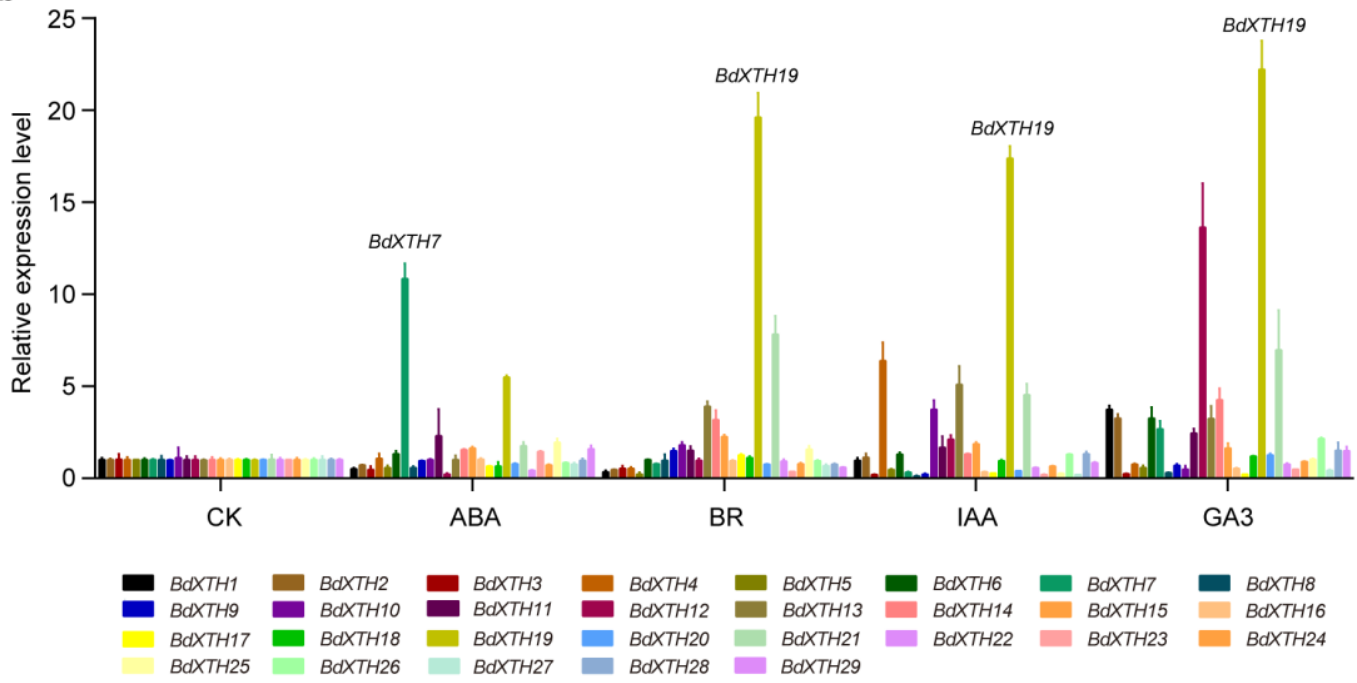




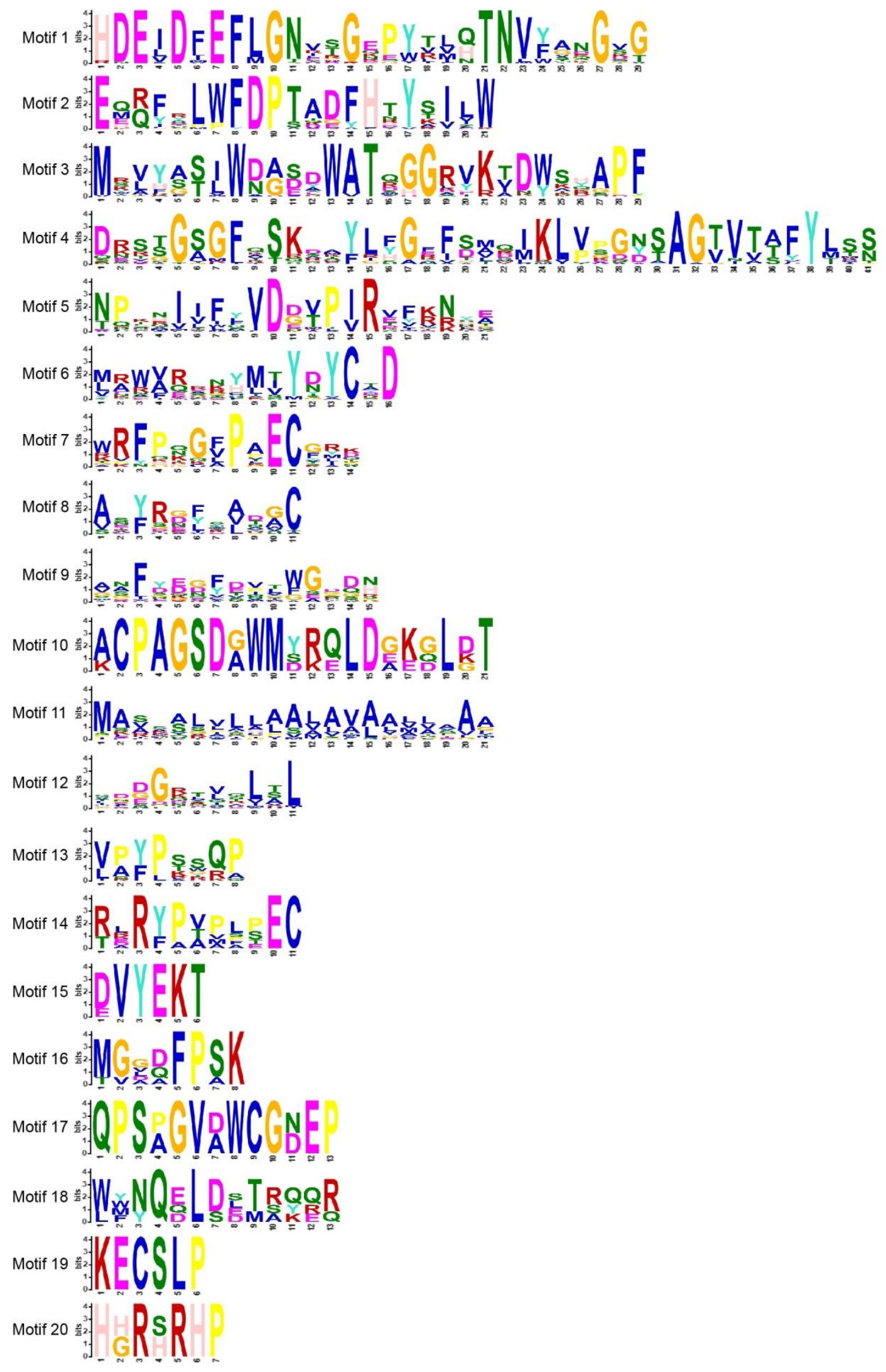



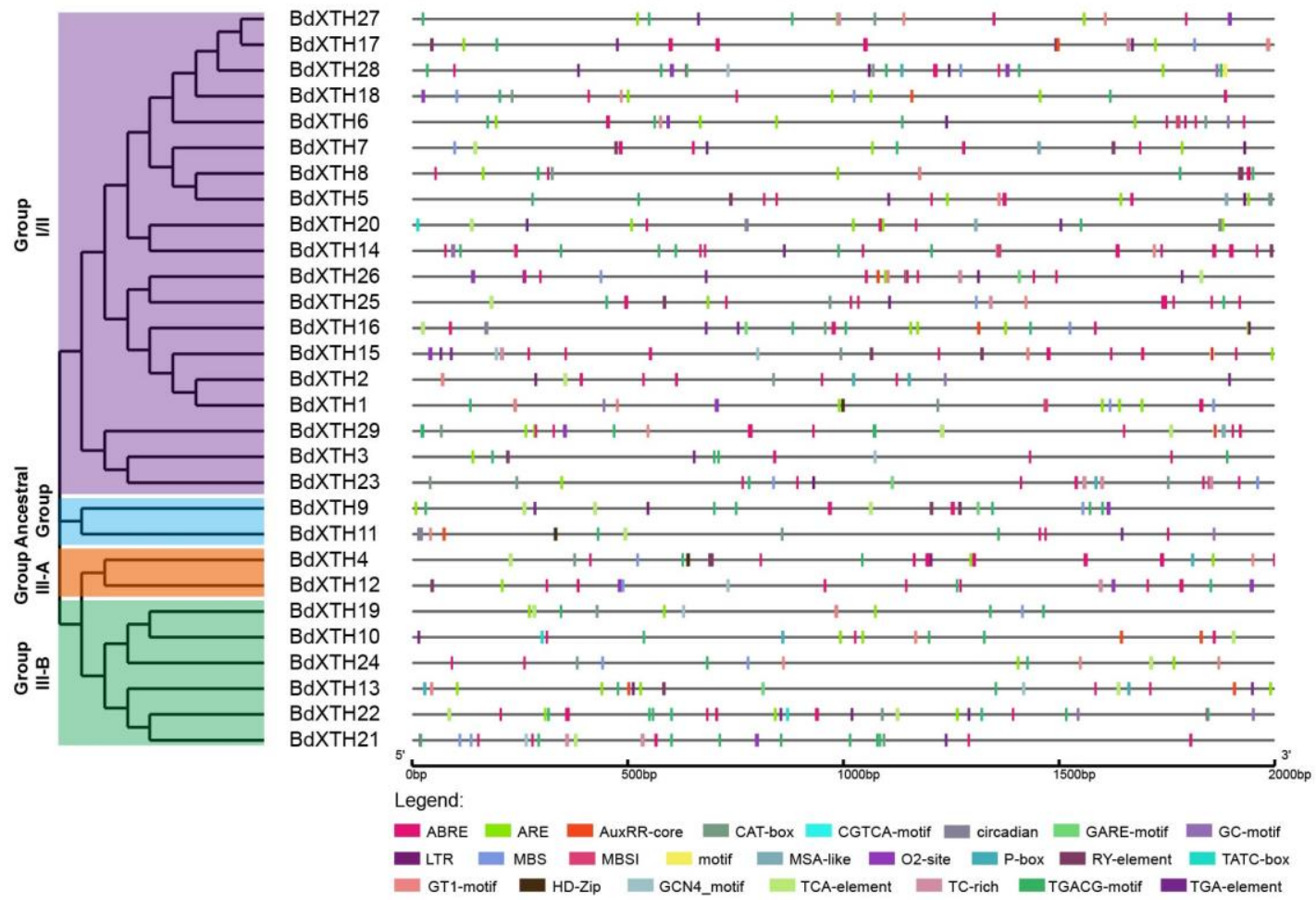
Table S2 Oligonucleotide primers used for qRT-PCR assays in this study.

\begin{tabular}{|c|c|}
\hline Primer name & Sequence \\
\hline Bradi1g09690.1F & CCGAGGTTTACCTGCGTTCT \\
\hline Bradi1g09690.1R & CCTCTCCGTAAGACTGTCGC \\
\hline Bradi1g09700.1F & CCGAGGTTTACCTGCGTTCT \\
\hline Bradi1g09700.1R & CCTCTCCGTAAGACTGTCGC \\
\hline Bradi1g25847.1F & GCGGTGTAACTATCAGAGA \\
\hline Bradi1g25847.1R & CTACCCATGCTCGTGTAT \\
\hline Bradi1g27867.1F & TTCGTTTCACAAGCATAGC \\
\hline Bradi1g27867.1R & AGTAGCATTGAGAACATCCA \\
\hline Bradi1g33810.1F & AGCTCAGCGACATGAGCTAC \\
\hline Bradi1g33810.1R & AGTTTCTCTCAACGGCGGAG \\
\hline Bradi1g33817.1F & CGTGGCAGTGTAAGAATC \\
\hline Bradi1g33817.1R & AAACGAGTGGAGAAACCT \\
\hline Bradi1g33827.1F & GAAGCCCGTGGATGTACCAG \\
\hline Bradi1g33827.1R & GTGTCGGCGCAGTAGTTGTA \\
\hline Bradi1g33840.1F & ATGCCTCGCTCATTCCACTC \\
\hline Bradilg33840.1R & TCGCTATTATCGCCGACACC \\
\hline Bradi1g44777.1F & CCAGACCAACGTCTTCGTCA \\
\hline Bradi1g44777.1R & CCTGTAGTCGTGGAAGTCGG \\
\hline Bradi1g68590.1F & AAGGAAGGAACGGAACGGAC \\
\hline Bradi1g68590.1R & GCTGCTGCTTCGCTAAACTC \\
\hline Bradi1g71937.1F & GAGGATGAAGATACCCGGCG \\
\hline Bradi1g71937.1R & AAAACGACGTGCTTGCCTTC \\
\hline Bradi1g77990.1F & ACGGATCGCTCCAAGAATCG \\
\hline Bradi1g77990.1R & CGTTAATCAATCGCCGCTGG \\
\hline Bradi3g02700.1F & TGAGTTCCTCGGCAACATCC \\
\hline Bradi3g02700.1R & GTCCACAGGATGGAGTAGCG \\
\hline Bradi3g10290.1F & ATCCGGCCAGTTAAGCGAAA \\
\hline
\end{tabular}




\begin{tabular}{|c|c|}
\hline Bradi3g10290.1R & GCCGGACACAAGTCCGATAA \\
\hline Bradi3g18590.1F & GGCAGTTGGCACGTTAGTTG \\
\hline Bradi3g18590.1R & CATCCAAATCGCCTCCCCAT \\
\hline Bradi3g18600.1F & TTTTGCCACCGTCGTTGTTC \\
\hline Bradi3g18600.1R & TCCTTGACACAGCAGCTACG \\
\hline Bradi3g18607.1F & GCGCGAGACAAGCACATGAT \\
\hline Bradi3g18607.1R & CAGTCCGAGGTGCATTCCTT \\
\hline Bradi3g18690.1F & AGTGAACAACGGGACAACCA \\
\hline Bradi3g18690.1R & CAGAACACCTACGGCCTCAC \\
\hline Bradi3g21337.2F & GGTTACTGCTACGACCGTCT \\
\hline Bradi3g21337.2R & CTGATCCCTGGACCTCGCTA \\
\hline Bradi3g31767.1F & GTCCGATGTACGGGTTCTCC \\
\hline Bradi3g31767.1R & GGCCTTGCTCCAATCAGTCT \\
\hline Bradi3g34227.1F & TACCGCCATGGCTTCTTCAG \\
\hline Bradi3g34227.1R & GACAGGTAGAAGGCGACGAC \\
\hline Bradi3g52307.1F & GACGCCGGATGATAGGACTG \\
\hline Bradi3g52307.1R & GCCGTGGAGGTAGTAATCCG \\
\hline Bradi4g16990.1F & CGCGCCCAATTAATCCAGTG \\
\hline Bradi4g16990.1R & TACGTACGCCAATCGACCAG \\
\hline Bradi4g29707.1F & GATGTGATCCCGCCATGACT \\
\hline Bradi4g29707.1R & AAATTCCGACCGGTCTCCAC \\
\hline Bradi5g20718.1F & GAGTTCCTGGGGAACGTCAG \\
\hline Bradi5g20718.1R & AACCACAGGTAGAACCGCTG \\
\hline Bradi5g20726.1F & TTAACGCGTGCAGAGGCTAT \\
\hline Bradi5g20726.1R & GGACAGACACACAGAGCGAA \\
\hline Bradi5g20734.1F & CAAACGAGGTTCTCCСТCCC \\
\hline Bradi5g20734.1R & AAATGTGATATGCGCGTGGC \\
\hline Bradi5g20742.1F & AAGTCAAGACGGACTGGTCG \\
\hline
\end{tabular}


Bradi5g20742.1R

Bradi5g22907.1F

Bradi5g22907.1R

BdUBC18-F

BdUBC18-R
CACGTACTCCTGCCCGTATC

GGCGTCGTCACTGCTTTCTA

GTACAGGTTCGTCTGCACCA

TGGAGGCACCTCAGGTCATTTTC

GTTGCTTTGCTGGCGAGCTAGAC

962

963 


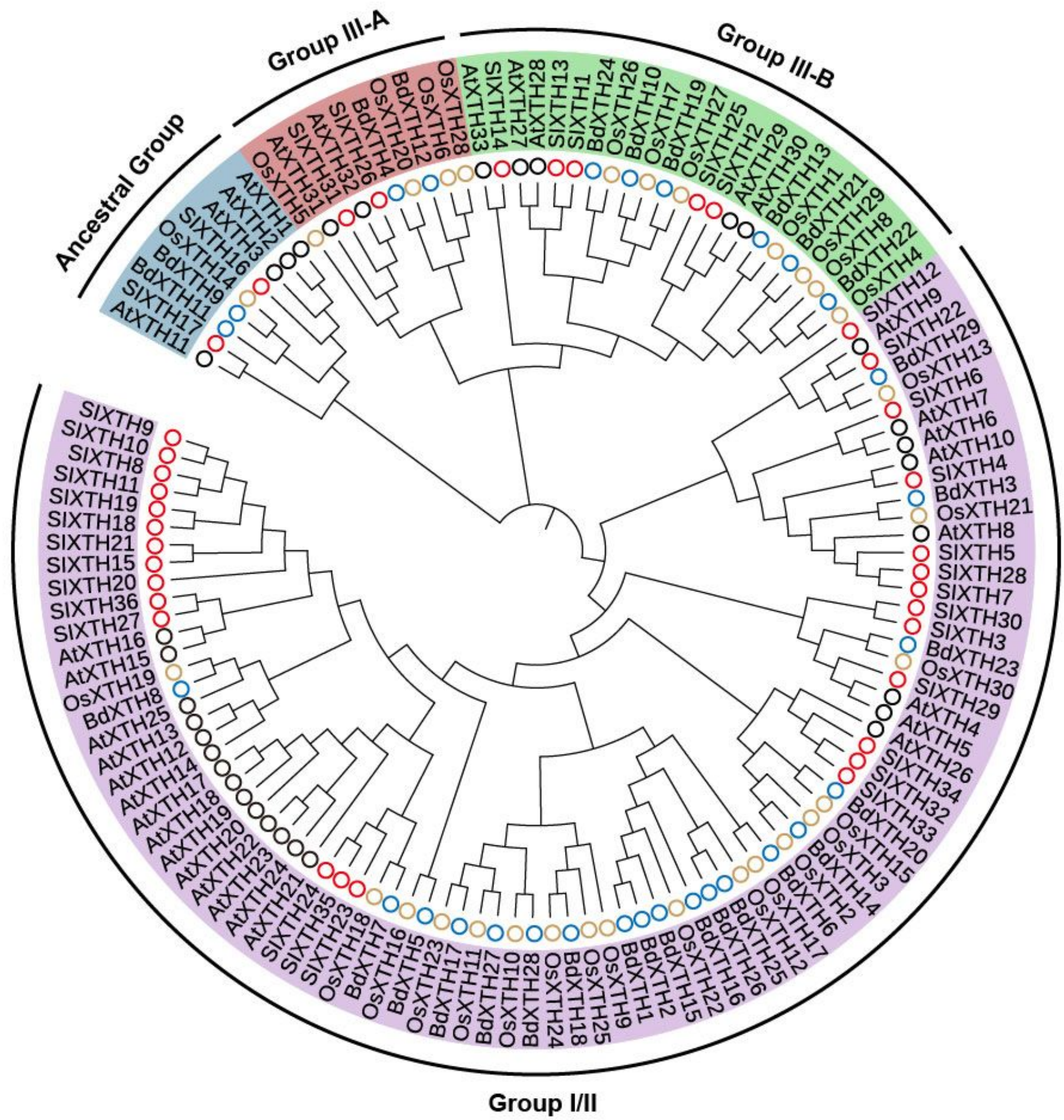

Figure 1

Phyloge netic relationships among XTH proteins from Brachypodium and three other plant species. The phylogenetic tree was constructed with the Neighbor Joining $(\mathrm{NJ})$ method as implemented in MEGA X software, and branch confidence was estimated by bootstrapping with 1,000 replicates. The open blue, 
gray, red, and black circles indicate proteins from Brachypodium , rice, tomato, and Arabidopsis, respectively. In addition, the XTH proteins are classified into three clades (Group I/II, Group III, and the Ancestral Group) Group). Proteins in Group I/II and the Ancestral Group are shown with purple and blue backgrounds, respectively. Group III is further divided into two subclades, Group III A and Group III B, which are indicated with red and green backgrounds, respectively.
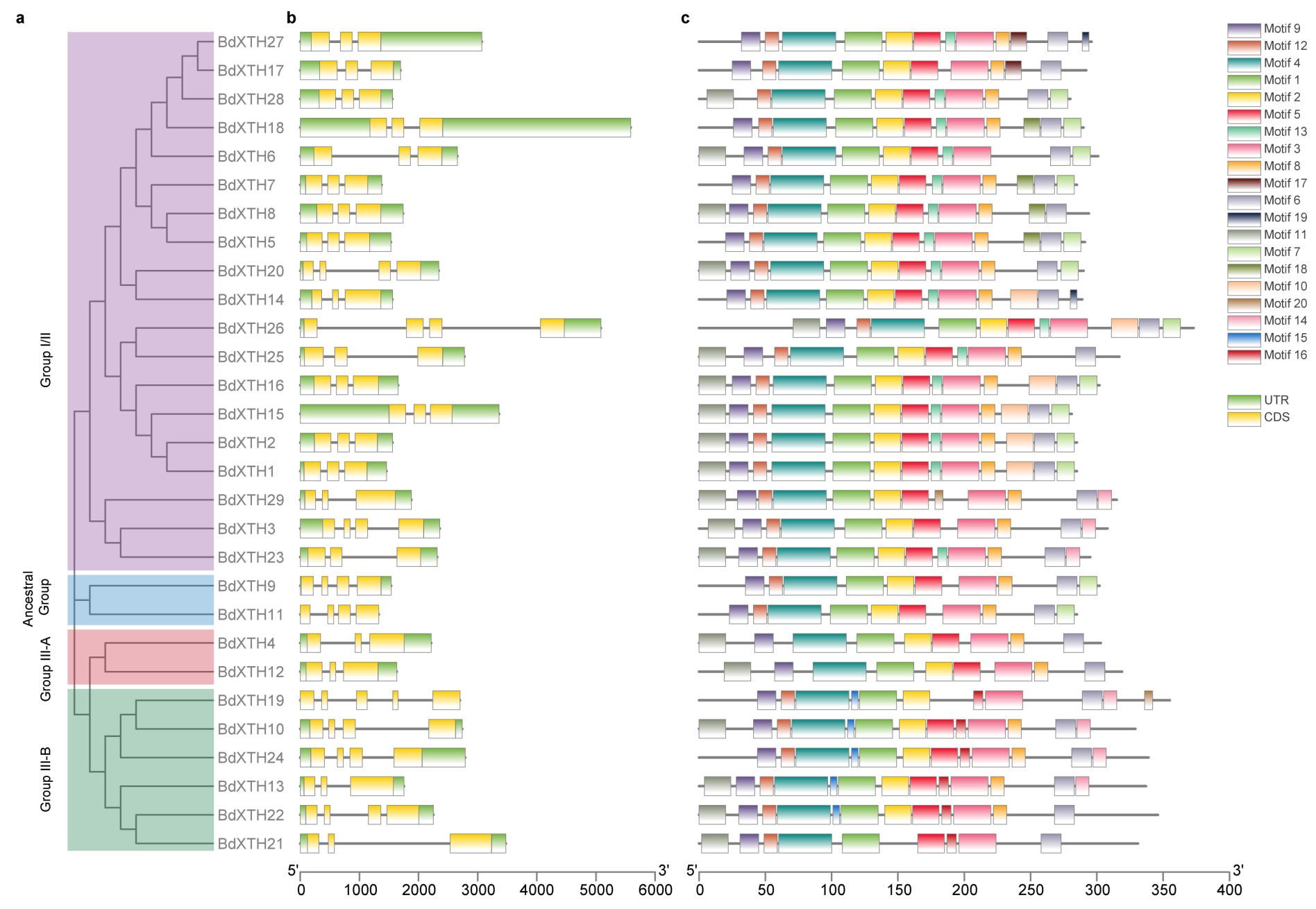

Figure 2

Unrooted neighbor joining phylogenetic tree, conserved protein motifs, and structural analysis of BdXTH genes. a ) Phylogenetic relationships of the XTH proteins in Brachypodium . Proteins from the four clades (Group I/II, Group III A and Group III B, and the Ancestral Group) are color coded as in Figure 1. (b) The structures of the 29 putative BdXTH genes. The UTRs, exons, and introns are represented by green boxes, yellow boxes, and black lines, respectively. (c ) Conserved motif analysis of the BdXTH proteins. The different motifs are indicated by different colored boxes numbered motif 1 to motif 20 . The structural features of the 20 motifs are shown in Fig S1. 


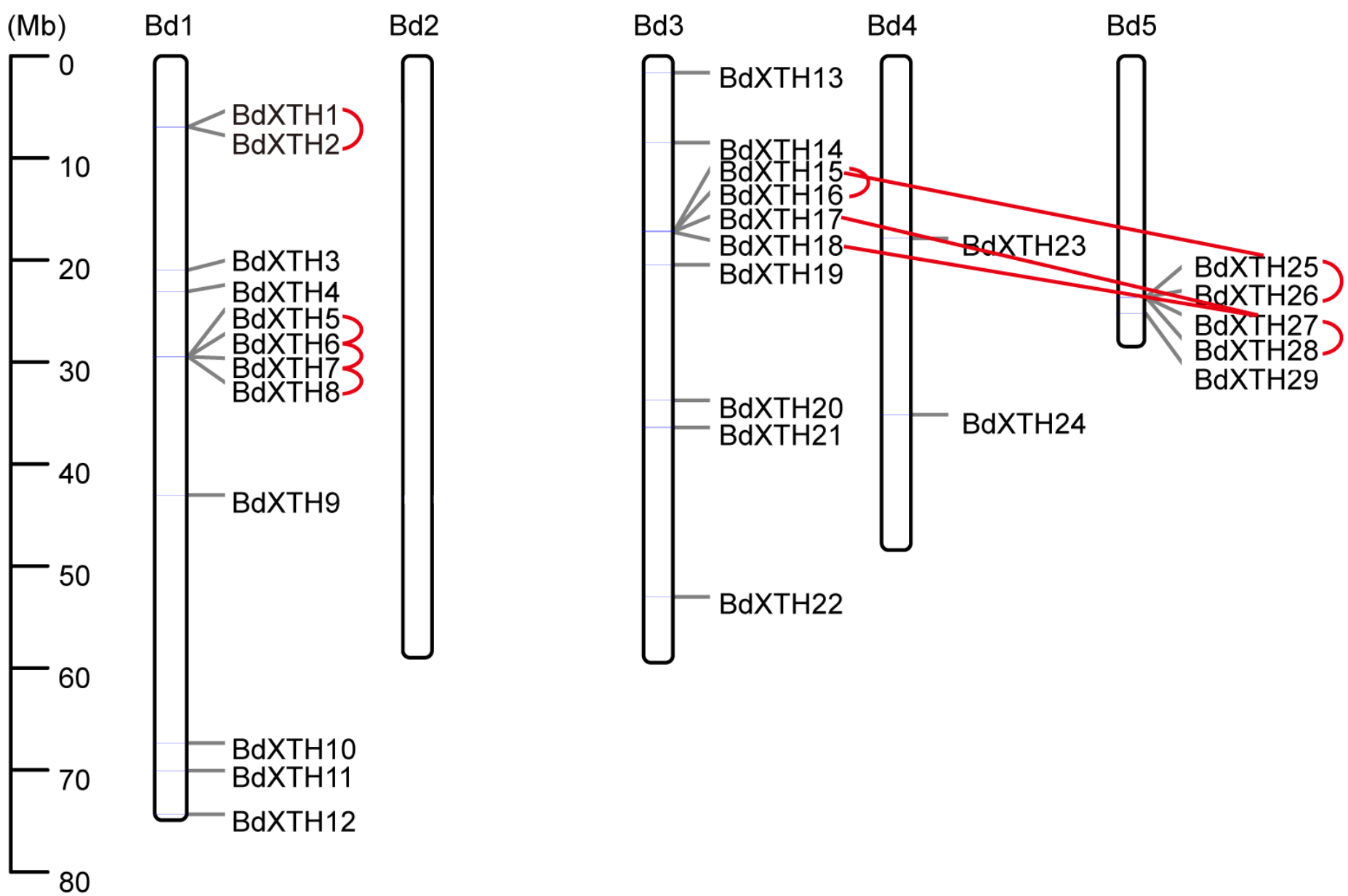

Figure 3

The physical locations of BdXTH genes on the five Brachypodium chromosomes. Tandemly duplicated gene pairs and segmentally duplicated genes are linked by red lines. The chromosome numbers are displayed at the top of each chromosome and the scale in megabases (Mb) is shown on the left. 


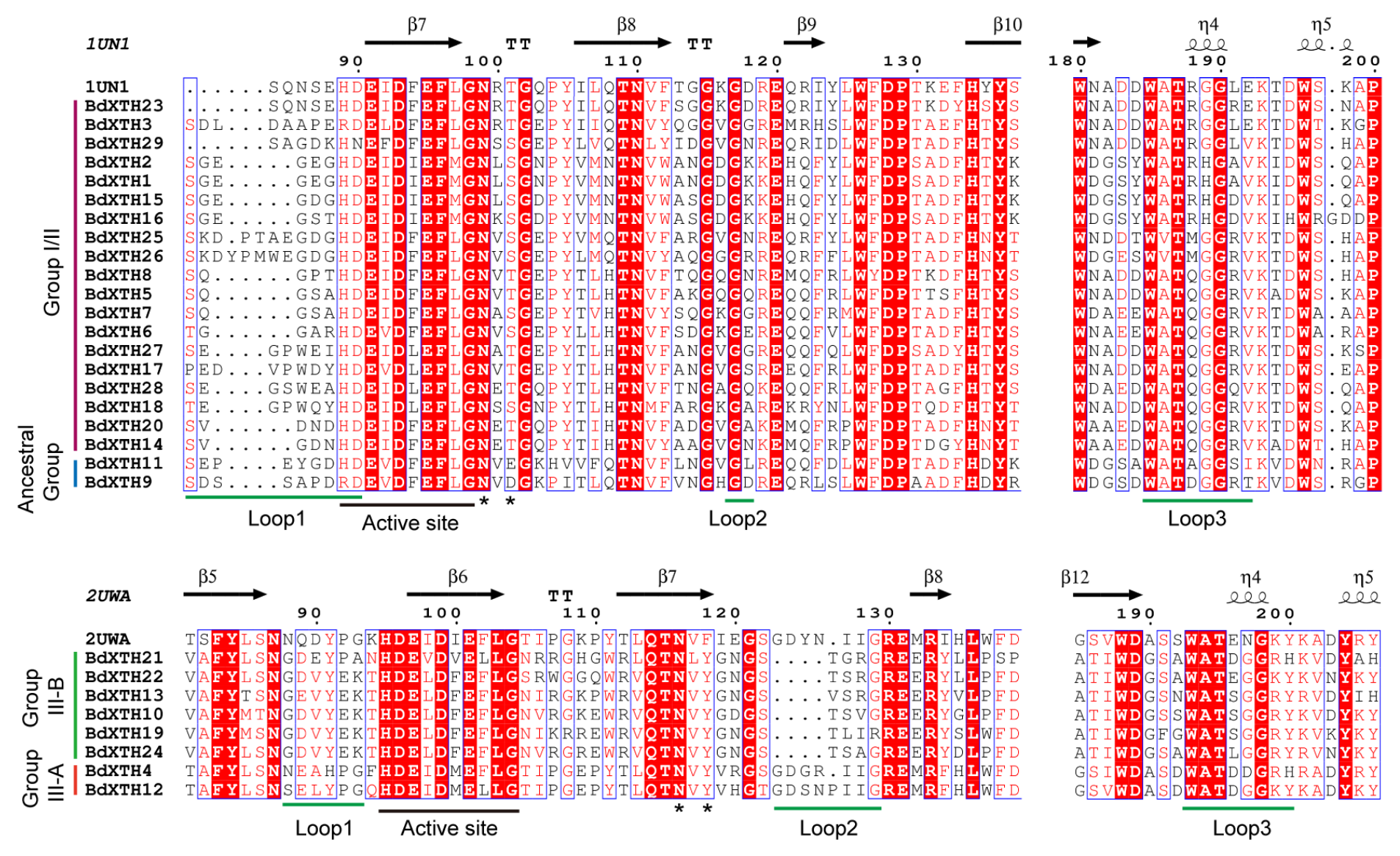

\section{Figure 4}

Structure based sequence alignment of BdXTH proteins. The structures of two proteins (PttXET16 34, PDB id: 1UN1; TmNXG1, PDB id: 2UWA) have been experimentally determined. Proteins in Group I/II and the Ancestral Group had similar structures to $1 \mathrm{UN1}$, and proteins in Group III show similar structures to 2UW A. The active site ( $E \times D \times E$ ), and loops 1, 2, and 3 are underlined in black and green, respectively . The $\mathrm{N}$ glycosylation site residues are indicated by asterisks. 


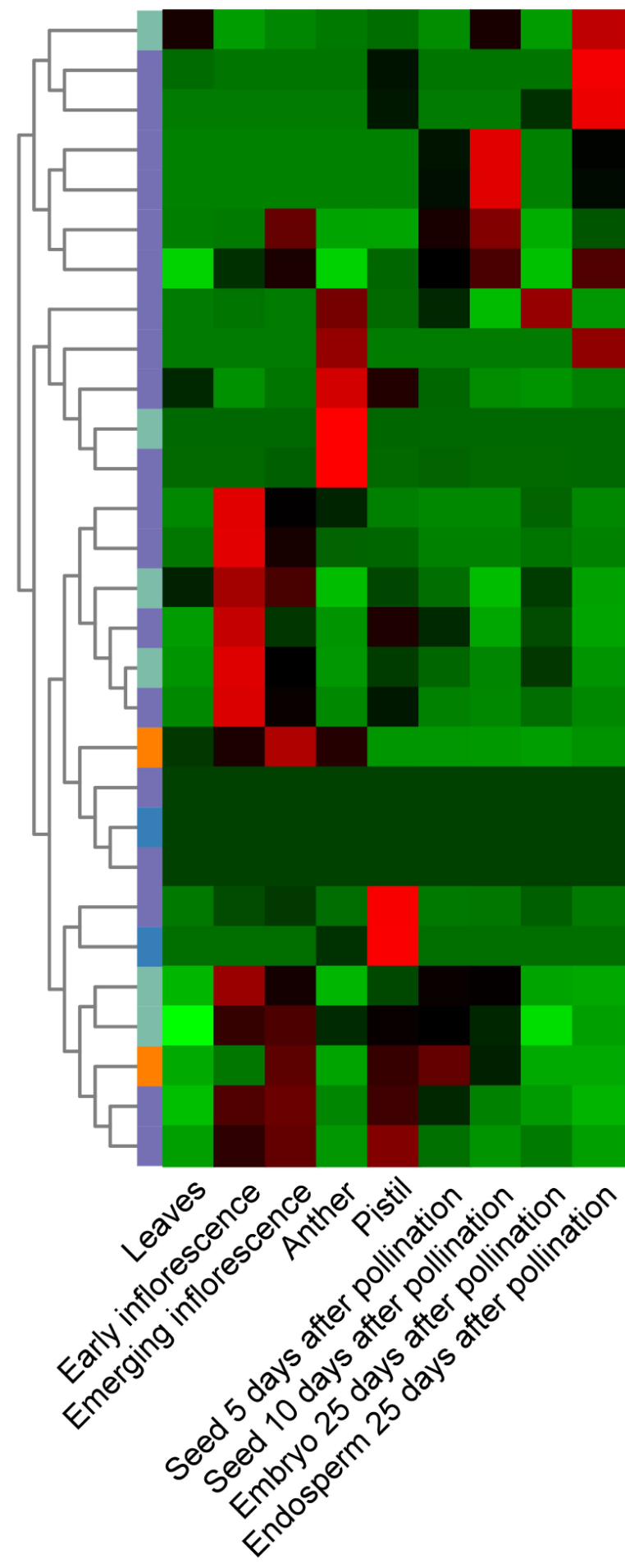

$B d X T H 21$

$B d X T H 26$

$B d X T H 27$

$\mathrm{BdXTH1}$

BdXTH2

$B d X T H 15$

$B d X T H 16$

$B d X T H 18$

$B d X T H 25$

$\mathrm{BdXTH7}$

$B d X T H 13$

BdXTH17

BdXTH14

$\mathrm{BdXTH23}$

$B d X T H 19$

$\mathrm{BdXTH3}$

BdXTH24

BdXTH29

$\mathrm{BdXTH4}$

$\mathrm{BdXTH28}$

$B d X T H 11$

$\mathrm{BdXTH2O}$

$\mathrm{Bd}$ XTH8

BdXTH9

BdXTH10

BdXTH22

$B d X T H 12$

$\mathrm{BdXTH5}$

$B d X T H 6$

\section{Figure 6}

Heat map showing the expression pattern of BdXTH genes in Brachypodium . Expression profiles from various tissues and developmental stages (leaves, early inflorescences, e merging inflorescences, anthers, pistils, seeds at 5 days after pollination, seeds at 10 days after pollination, embryos, and endosperm) were downloaded from the NCBI database (SRP008505). The relative expression levels are represented by the colored bars. Red and green boxes indicate high and low expression levels, respectively. 


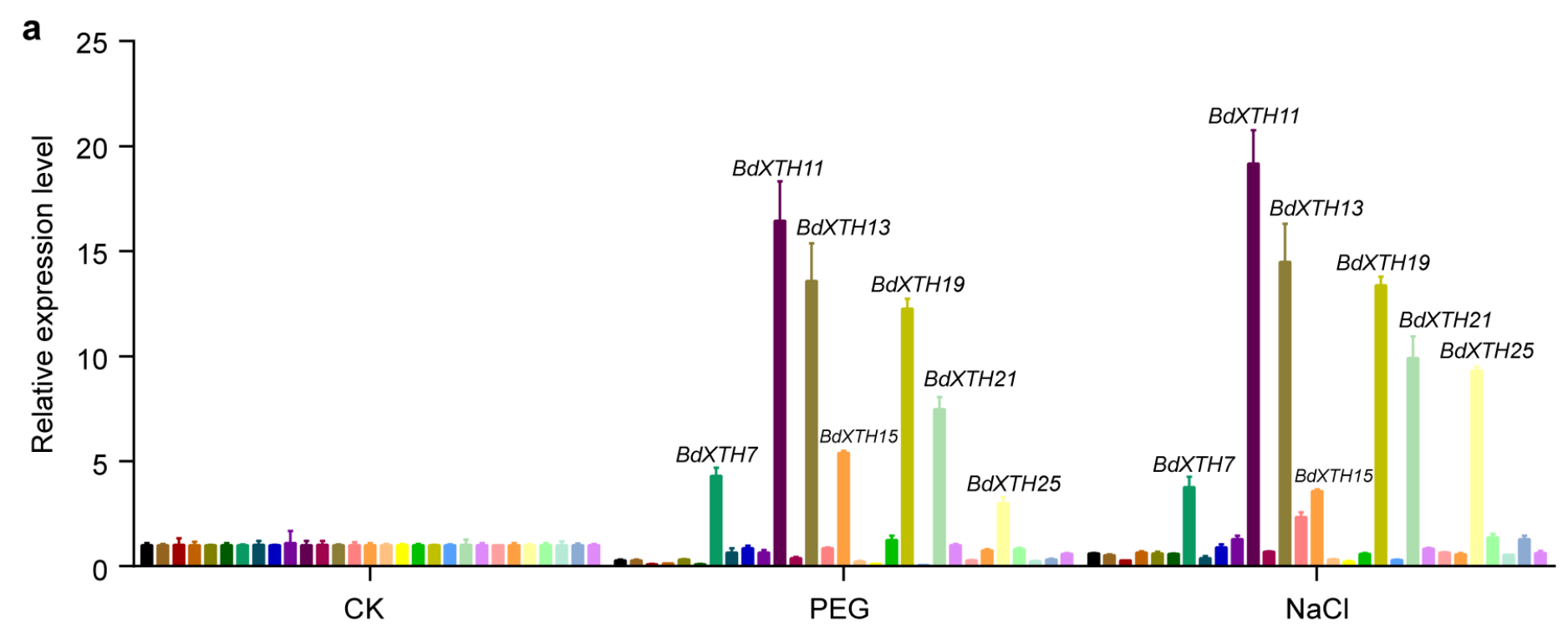

b

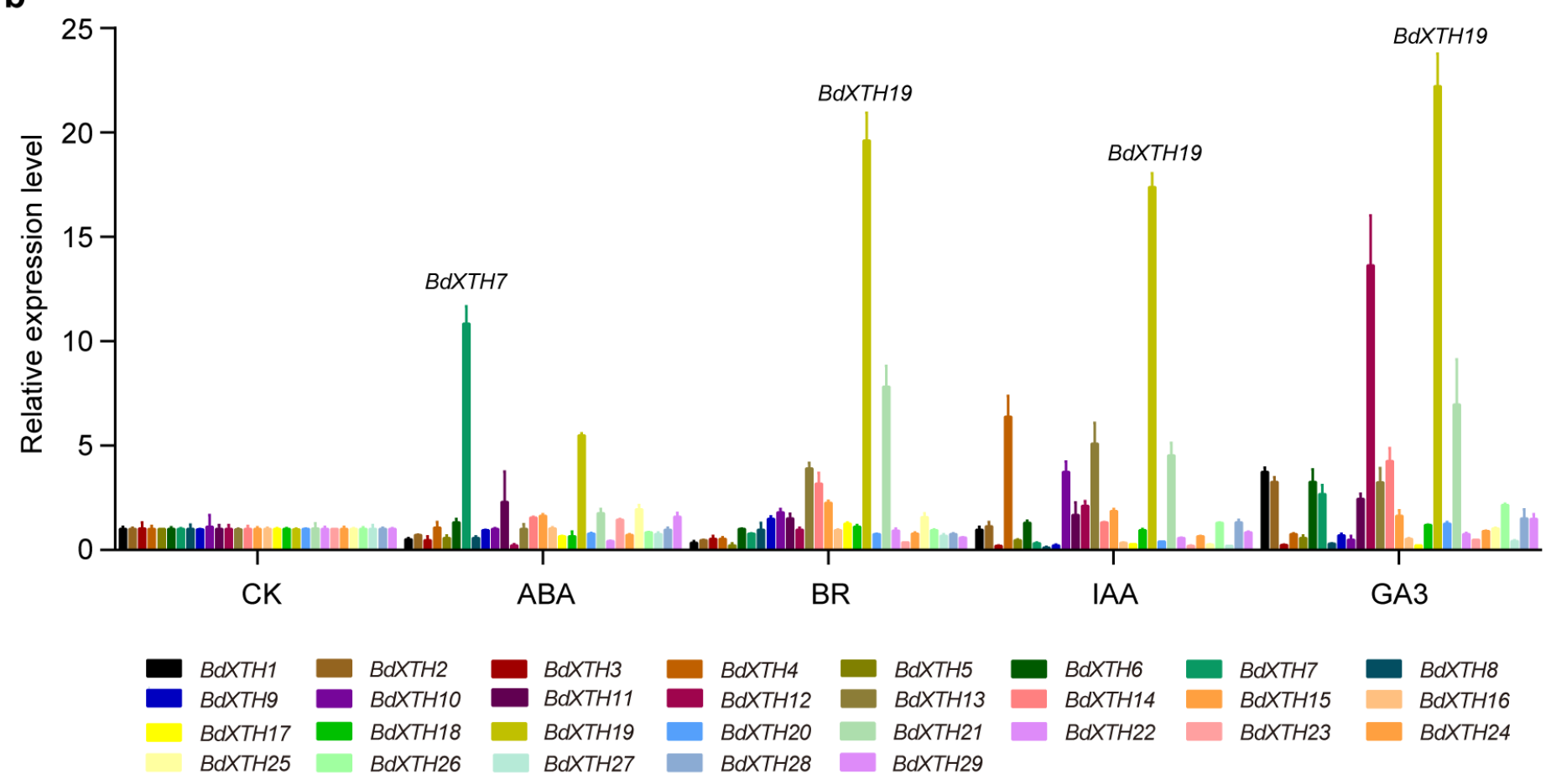

Figure 7

Expression analysis of BdXTH genes under different conditions. Quantitative real time polymerase chain reaction (qRT PCR) analysis of BdXTH gene expression in response to ab iotic stresses (drought and salinity) ( a ), and phytohormone treatments (ABA, BR, IAA, and GA3) (b). The means $\pm S D$ of three biological replicates are presented.

\section{Supplementary Files}

This is a list of supplementary files associated with this preprint. Click to download. 
- Fig.S1.jpg

- Fig.S2.pdf

- Fig.S3.pdf

- Fig.S4.tif

- Tables1.xlsx

- TableS2.xlsx 